\title{
Data Oscillation Resolution of Propellant Flowmeter Used in FASTRAC Engine Testing
}

Team Member Inputs by

TD53/Mike Martin

TD72/Johnny Heflin

TD61/Mary Beth Koelbl

TD63/Tom Nesman

TD52/ Gary Hicks
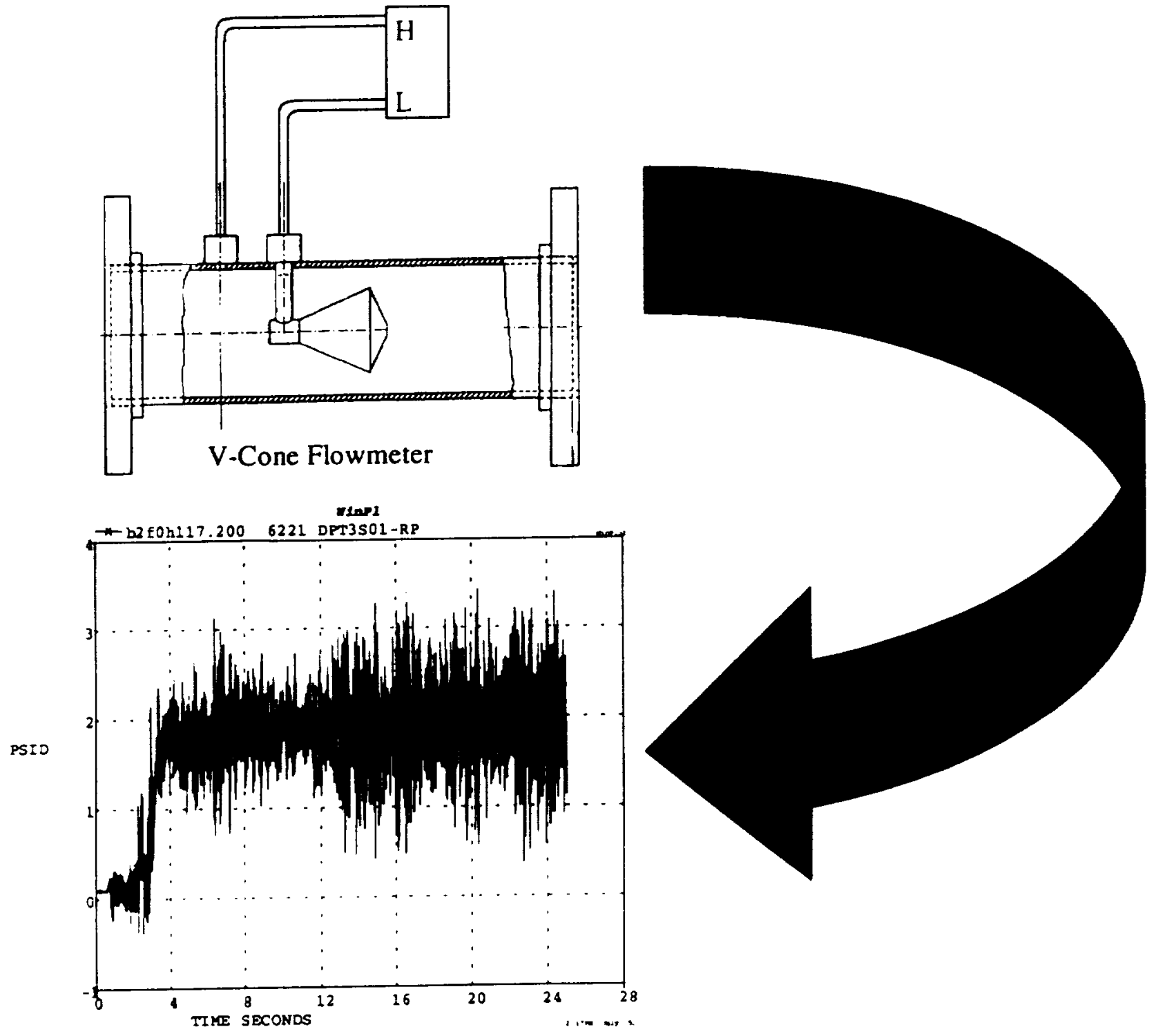

February 2000 


\section{TABLE OF CONTENTS}

Title

Page

List of Figures

List of Tables

Acronyms

Summary

Introduction

Description of Problem

Initial Facility Configuration

Investigation

LOX Cold Flow Test Configuration

LOX Cold Flow Test Results

RP-1 Cold Flow Test Configuration

RP-1 Cold Flow Test Results

Testing Results with Stellar Transducers

Testing Results with Rosemount Transducers

Configuration Summary

Recommendations

References

Appendix A - HTF RP-1 V-Cone Validation Test Procedure Appendix B - HTF RP-1 V-Cone Validation Test Configuration 


\section{LIST OF FIGURES}

Figure

Title

Page

1 PR-1 Flowmeter Oscillations 4

2 LOX Flowmeter Oscillations 5

3 Calculated Flow Rate 6

4 Initial PTA-1 V-Cone Flowmeter Configuration 7

$5 \quad$ Initial HTF V-Cone Flowmeter Configuration 8

6 PTA-1 LOX Flowmeter Configuration 10

$7 \quad$ PTA-1 LOX Flowmeter Test Results 11

$8 \quad$ Comparison of Measured LOX Flow Rates 12

9 HTF RP-1V-Cone Validation Test $1 \quad 13$

10 HTF Test 1 First Pressure Setting 15

11 HTF Test 1 Third Pressure Setting 16

12 HTF RP-1V-Cone Validation Test $1 \quad 17$

Poor Response of Filter Snubber

13 HTF RP-1V-Cone Validation Test 2

Good Response of Filter Snubber

$\begin{array}{lll}14 & \text { Filter Snubber on HTF RP-1V-Cone Validation Test } 4 & 19 \\ 15 & \text { Calculated Flow Rate Data } & 20\end{array}$

16 Rosemount Delta Pressure Transducer Oscillation Level 21

17 HTF RP-1 V-Cone Validation Test $3 \quad 22$

18 Rosemount Zero Shift Data 23

19 HTF RP-1V-Cone Validation Test $4 \quad 24$

$20 \quad$ Zero Shift Curve 25

$21 \quad V$-Cone and Turbine Flowmeter Flow Rates 26

22 Recommended PTA-1 RP-1 Flowmeter Configuration 29

23 Recommended HTF RP-1 Flowmeter Configuration 30

\section{List of Tables}

Table

Title

Page

$1 \quad$ PTA-1 Flowmeter Test Data 3

2 Test Results Summary $\quad 27$ 


\title{
ACRONYMS
}

\author{
GOX \\ HTF \\ $\mathrm{Lbm} / \mathrm{sec}$ \\ LOX \\ LN2 \\ MSFC \\ PID \\ Psia \\ PSID \\ PTA-1 \\ RP-1 \\ RPM \\ Snubber Type EA \\ Snubber Type EH \\ Snubber Type EL \\ Snubber Type EW \\ SSC \\ WinPlot \\ Gaseous Oxygen \\ Horizontal Test Facility \\ Pounds mass per second \\ Liquid Oxygen \\ Liquid Nitrogen \\ Marshall Space Flight Center \\ Parameter identification \\ Pounds per square inch absolute pressure \\ Pounds per square inch differential pressure \\ Propulsion Test Article 1 \\ Rocket Propellant 1 \\ Revolutions per minuet \\ Air service \\ Heavy oil service \\ Light oil service \\ Water service \\ Stennis Space Center \\ MSFC computer program to plot data
}




\section{SUMMARY}

The Stennis Space Centers horizontal test facility. Marshal Space Flight Centers propulsion test article and the X-3+ flight vehicle are designed with V-Cone flowmeters for measurement of both RP-1 and LOX flow rates for Fastrac en@ine testing. Delta pressure transducer data from these flowmeters are used to calibrate the RP- 1 and LOX mixture ratio in the Fastrac engine. Data from the V-Cone flowmeter delta pressure transducers have excessive oscillation. The delta pressure oscillations have caused flowrate data fluctuations that interfered with making the accurate readings necessary to calibrate the RP-1 and LOX mixture ratio required for Fastrac engine operation.

The objective of this report is to document the flowmeter data oscillation problem and the method used to obtain more reliable flowmeter data.

The scope of work covered by this report is the LOX and RP-1 feedline flowmeters, filters and delta pressure transducer data used to support Fastrac engine testing. The scope of work includes test configurations conducted on both the horizontal test facility (HTF) and the propulsion test article (PTA-1) at Stennis Space Center (SCC).

The typical oscillation amplitude in the HTF LOX flowmeter data is 2 to 5 PSID at a mean differential pressure of 2.5 PSID using a Stellar delta pressure transducer. The oscillation amplitude in the PTA-1 LOX flowmeter data is 4 to 7 PSID at a mean differential pressure of 3.9 PSID using a Stellar delta pressure transducer.

A combination of Stellar and Rosemount delta pressure transducers were tested with and with out snubbers. The most reliable LOX flowmeter data was obtained wile using a type EA snubber with a Stellar delta pressure transducer. The oscillation amplitude in HTF LOX flowmeter data was reduced to 0.3 PSID at a mean differential pressure of 2.5 PSID. The oscillation amplitude in PTA-1 LOX flowmeter data was reduced to 0.5 to 2 PSID at a mean differential pressure of 4.5 PSID. The sense lines were long enough to ensure that GOX (from ambient heat transfer) was at the snubber location.

The approximate oscillation amplitude in the HTF RP-1 flowmeter is from 1 to 2 PSID at a mean differential pressure of 2 PSID using a Stellar delta pressure transducer.

A turbine flowmeter in conjunction with several configurations of Stellar and Rosemount delta pressure transducers with different types of snubbers were tested. The most reliable RP-1 flowmeter data was obtained while using a Rosemount delta pressure transducer with out a snubber. The oscillation amplitude in HTF RP-1 flowmeter data was reduced to 0.2 PSID at a mean differential pressure of 1.5 PSID. The oscillation amplitude in PTA-1 RP-1 flowmeter data was reduced to 0.2 PSID at a mean differential pressure of 3.3 PSID. The PTA-1 PR-I flowmeter sense lines were kept horizontal to the flowmeter sense line ports to reduce any elevation effects on the delta pressure measurement. The HTF RP-1 flowmeter sense lines were primed with RP-1 prior to test. 


\section{INTRODUCTION}

The Fastrac Engine is undergoing a series of tests at Stennis Space Center (SSC) on both the horizontal test facility (HTF) and the propulsion test article (PTA-1). The SSC HTF and PTA-1 facilities have experienced feed system pressure oscillations. These feed system pressure oscillations cause flowrate oscillations. The oscillations flowrate interfere with making accurate flow readings which are required to calibrate the RP-1 to LOX mixture ratio of the Fastrac Engine. A method of reliably measuring steady-state flowrate was identified as a constraint for testing on both PTA- 1 and HTF Fastrac Engines. 


\section{DESCRIPTION OF PROBLEM}

The SSC HTF facility. MSFC PTAl and X-3+flight vehicle are designed with V-Cone flowmeters for measurement of both RP-1 and LOX R.us. The V-Cone foumeters are also used on the helium pressurization system for the PT. -11 LOX and $\mathrm{ki}-1$ tanks. $V$ Cone flowmeters are differential pressure-type flow measurement deviees. For initial hot-fire testing on HTF and cold flow tests on PTA-1. the differential pressure was measured with Stellar delta pressure transducers. During these tests. there was considerable scatter/oscillation in the flowmeter data [1] which interfered with determining an accurate steady-state flow rate. Table 1 shows the mean measured delta pressure and the amplitude of the oscillations about the mean which were observed on PTA-1. Figure 1 depicts the typical delta pressure oscillations [2] seen in the HTF RP-1 flowmeter. The approximate oscillation amplitude shown here is from 1 to 2 PSID at a mean differential pressure of 2 PSID. Figure 2 depicts the typical delta pressure oscillations[2] seen in the HTF LOX flowmeter. The typical oscillation amplitude in LOX is 2 to 5 PSID at a mean differential pressure of 2.5 PSID.

Table 1 PTA-1 Flowmeter Test Data

\begin{tabular}{|c|c|c|c|c|}
\hline Test & $\begin{array}{l}\text { FM1 (PID6604) } \\
\text { Helium }\end{array}$ & $\begin{array}{l}\text { FM2 (PID6605) } \\
\text { Helium }\end{array}$ & $\begin{array}{l}\text { FM3 (PID6635) } \\
\text { RP-1 }\end{array}$ & $\begin{array}{l}\text { FM4 (PID6614) } \\
\text { LOX }\end{array}$ \\
\hline He Flow Test & $\begin{array}{l}0.6 \text { PSID noise at } \\
0 \text { PSID delta P }\end{array}$ & $\begin{array}{l}0.5 \text { PSID noise at } \\
2 \text { PSID delta } P\end{array}$ & $\begin{array}{l}\text { Min. noise at } 0 \\
\text { PSID delta } P\end{array}$ & $\begin{array}{l}\text { Min. noise at } 0 \\
\text { PSID delta } P\end{array}$ \\
\hline $\begin{array}{l}\text { Facility } \\
\text { Validation }\end{array}$ & $\begin{array}{l}0.9 \text { PSID noise at } \\
.15 \text { PSID delta } P\end{array}$ & $\begin{array}{l}0.2 \text { PSID noise at } \\
\text { O PSID delta } P \\
\end{array}$ & $\begin{array}{l}\text { Min. noise at } 0 \\
\text { PSID delta } P\end{array}$ & $\begin{array}{l}\text { Min. noise at } 0 \\
\text { PSID delta } P\end{array}$ \\
\hline $\begin{array}{l}\text { RP-1 Tanking } \\
\text { Test \# } 1\end{array}$ & $\begin{array}{l}0.9 \text { PSID noise at } \\
.14 \text { PSID delta } P\end{array}$ & $\begin{array}{l}\text { Min. noise at } 0 \\
\text { PSID delta } P\end{array}$ & $\begin{array}{l}0.12 \text { PSID noise at } \\
.1 \text { PSID delta } P\end{array}$ & $\begin{array}{l}\text { Min. noise at } 0 \\
\text { PSID delta } P\end{array}$ \\
\hline $\begin{array}{l}\text { RP-1 Tanking } \\
\text { Test \# } 2\end{array}$ & $\begin{array}{l}0.65 \text { PSID noise at } \\
.06 \text { PSID delta P }\end{array}$ & $\begin{array}{l}\text { min noise at } 0 \\
\text { PSID delta } P\end{array}$ & $\begin{array}{l}\text { 6.9 PSID noise at } \\
\text { 3.9 PSID delta P }\end{array}$ & $\begin{array}{l}\text { Min. noise at } 0 \\
\text { PSID delta } P\end{array}$ \\
\hline $\begin{array}{l}\text { PTA-1 LN2 } \\
\text { Tanking Test }\end{array}$ & $\begin{array}{l}\text { Min. noise at } 0 \\
\text { PSID delta } P\end{array}$ & $\begin{array}{l}2 \text { PSID noise at } 2 \\
\text { PSID delta } P\end{array}$ & $\begin{array}{l}.04 \text { PSID noise at } \\
\text { 0 PSID delta } P\end{array}$ & $\begin{array}{l}\text { 3.8 PSID noise at } \\
\text { 3.5 PSID delta } P\end{array}$ \\
\hline He Flow Test & $\begin{array}{l}\text { 1 PSID noise at } \\
\text { 2.9 PSID delta P }\end{array}$ & $\begin{array}{l}\text { 1.4 PSID noise at } \\
\text { 2 PSID delta } P\end{array}$ & $\begin{array}{l}\text { min noise at } 0 \\
P S I D \text { delta } P\end{array}$ & $\begin{array}{l}\text { Min. noise at } 0 \\
\text { PSID delta P }\end{array}$ \\
\hline $\begin{array}{l}\text { PTA-1 LOX } \\
\text { Tanking Test }\end{array}$ & $\begin{array}{l}0.45 \text { PSID noise at } \\
.03 \text { PSID delta } P\end{array}$ & $\begin{array}{l}\text { 1.1 PSID noise at } \\
2 \text { PSID delta } P\end{array}$ & $\begin{array}{l}\text { min noise at } 0 \\
\text { PSID delta } P\end{array}$ & $\begin{array}{l}0.03 \text { PSID noise } \\
\text { at } .5 \text { PSID delta P }\end{array}$ \\
\hline $\begin{array}{l}\text { Electrical } \\
\text { Diagnosis Test }\end{array}$ & $\begin{array}{l}.45 \text { PSID noise at } \\
\text { O PSID delta } P\end{array}$ & $\begin{array}{l}\text { Min. noise at } 0 \\
\text { PSID delta } P\end{array}$ & $\begin{array}{l}\text { Min. noise at } 0 \\
\text { PSID delta P }\end{array}$ & $\begin{array}{l}\text { Min. noise at } 0 \\
\text { PSID delta P }\end{array}$ \\
\hline $\begin{array}{l}\text { LOX \& RP-1 } \\
\text { Tanking test } \\
\text { TPS-BBM-324 }\end{array}$ & $\begin{array}{l}\text { clipped at }+6.68 \& \\
-6.7 \text { PSID delta P }\end{array}$ & $\begin{array}{l}0.01 \text { PSID noise at } \\
\text { 2.2 PSID delta } P\end{array}$ & $\begin{array}{l}0.02 \text { PSID noise at } \\
\text { 4.2 PSID delta } P\end{array}$ & $\begin{array}{l}\text { 4 PSID noise at } \\
\text { 4.1 PSID delta P }\end{array}$ \\
\hline
\end{tabular}




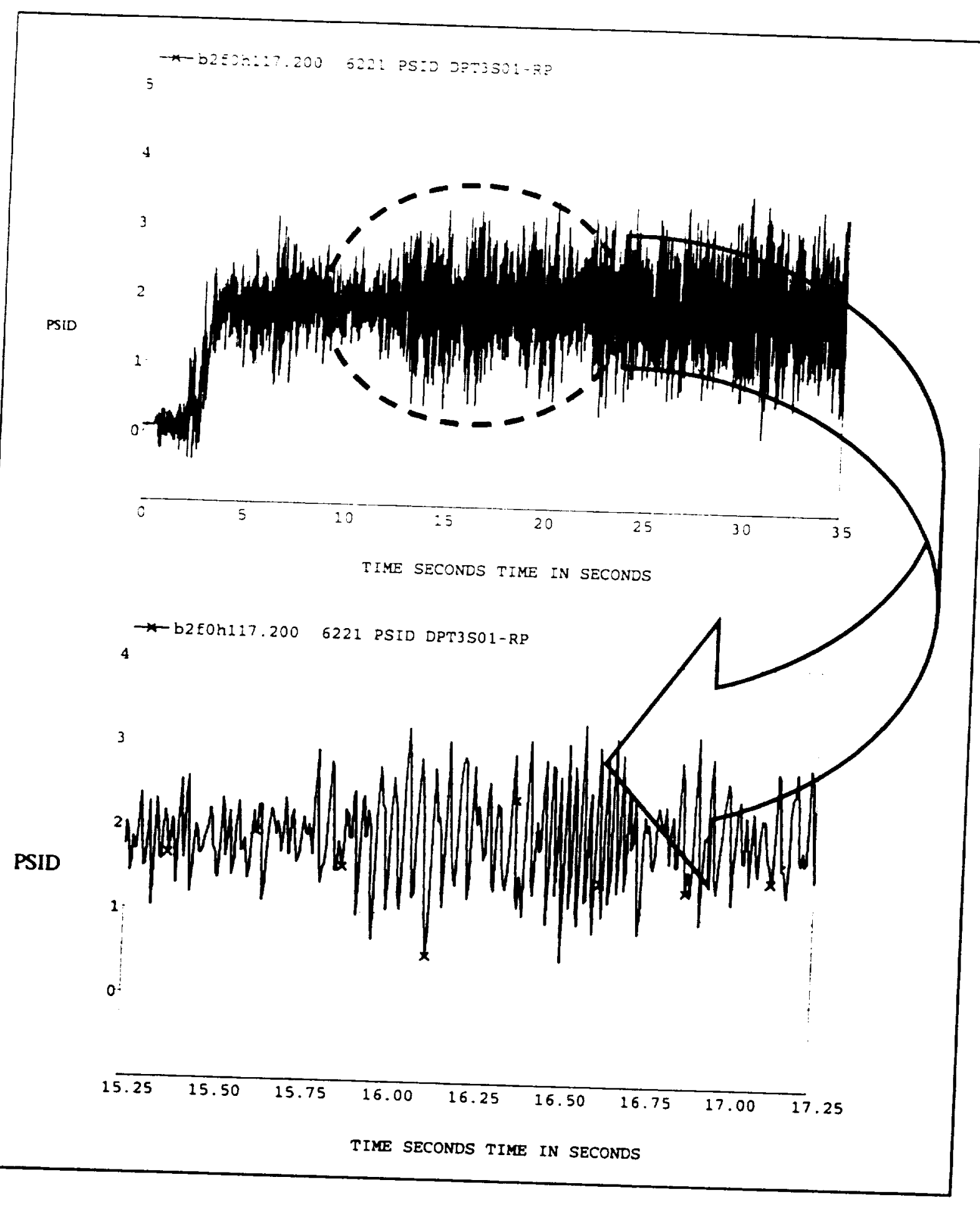

Figure 1

RP-1 Flowmeter Data Oscillations 
Description of Problem (continued)

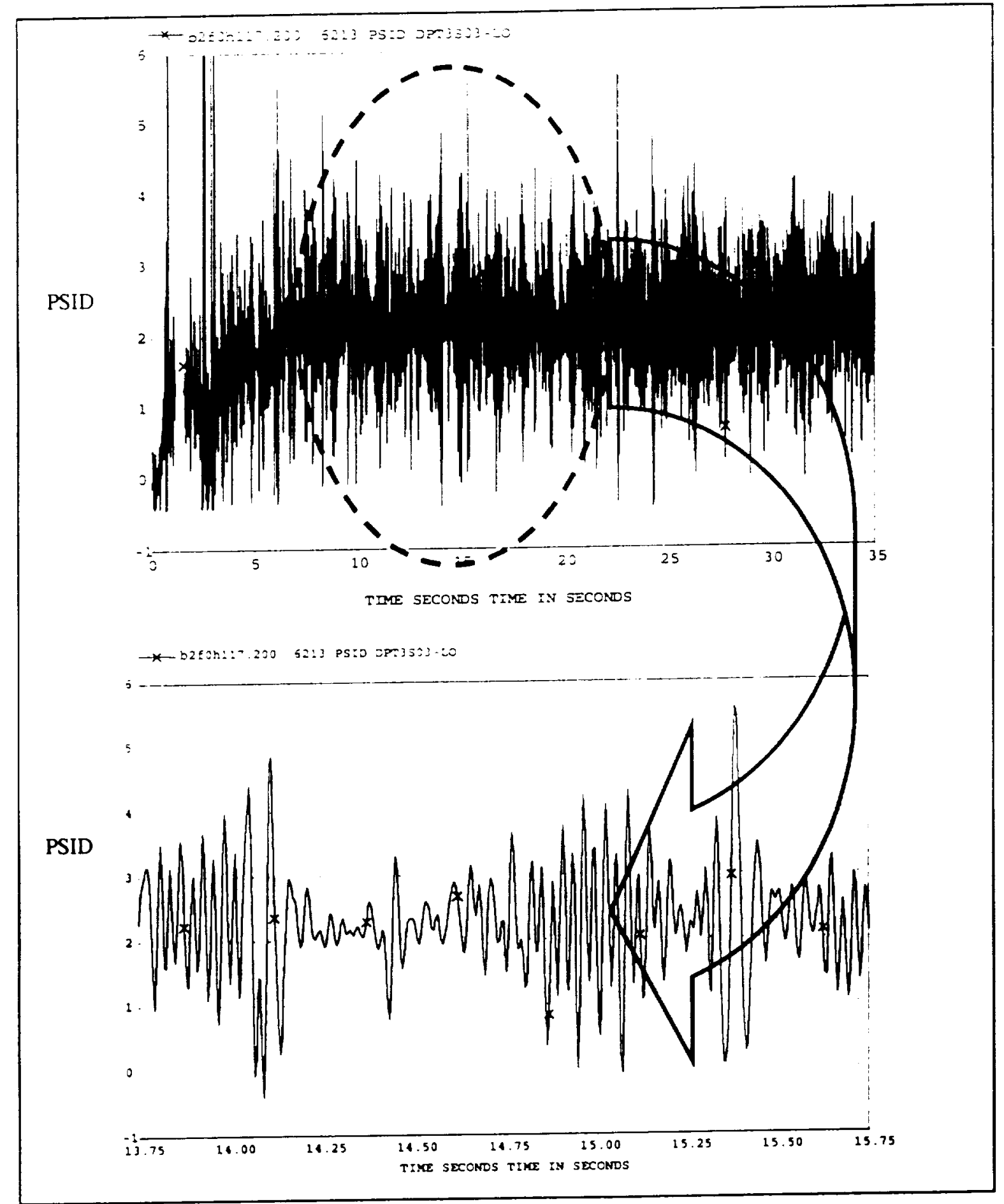

Figure 2

LOX Flowmeter Data Oscillations 
The oscillation levels[2] impact the accuracy in the calculated flow rate as shown in Figure 3. The oscillation level also masks the transient responie in the flow rate data.

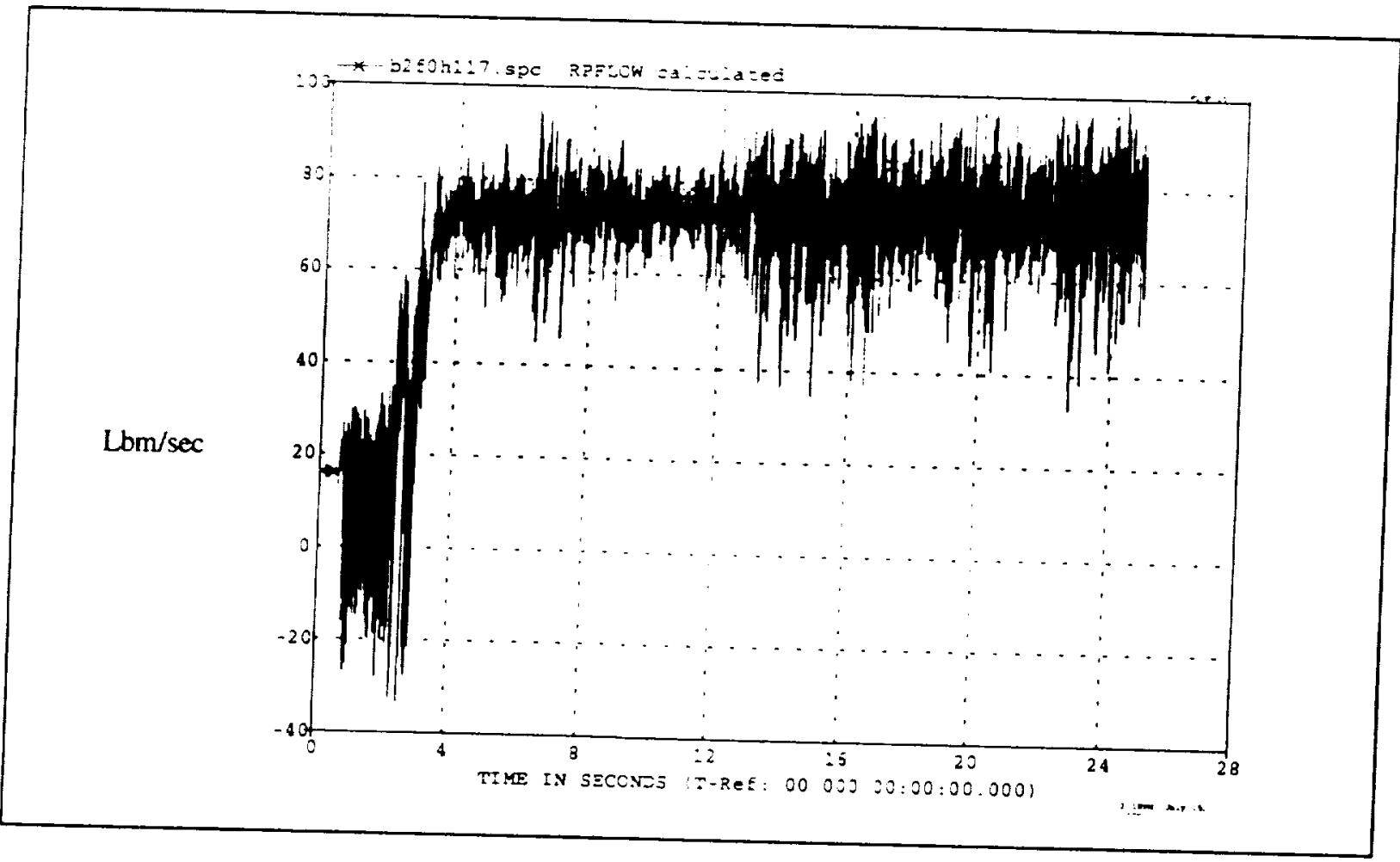

Figure 3

Calculated Flow Rate

A team was formed to resolve the flow measurement issues. It included personnel with experience in systems analysis, unsteady flows, and instrumentation, as well as the end users of the data. The team was tasked with recommending a flow measurement technique that would provide reliable steady-state flowrate data for both LOX and RP-1 on PTA-1 and HTF. The primary objective of the team was not to determine the source of the oscillations but to find a way to measure the flow with the oscillations present. 


\section{INITIAL FACILITY CONFIGURATION}

Figures 4 and 5 depict the initial $V$-cone flowmeter installation and the routing of the delta pressure transducer sense lines for PTA-1 and HTF respectively. Siellar delta pressure transducers were used for the delta pressure measurement on all tests. The PTA1 flowmeter configuration is per MSFC drawing 96M30110 for RP-1,96M30135 for LOX. 96M30195 for LOX Tank Helium pressurization and 96M30199 for RP-1 Tank Helium pressurization. The HTF flowmeter configuration is per SSC drawing MSK-1320018-LCT/PTAl for RP-1 and MSK-132-0017-LCT/PTA1 for LOX. The sense lines between all of the $\mathrm{V}$-Cone flowmeters and the Stellar delta pressure transducers were specified to be field routed.

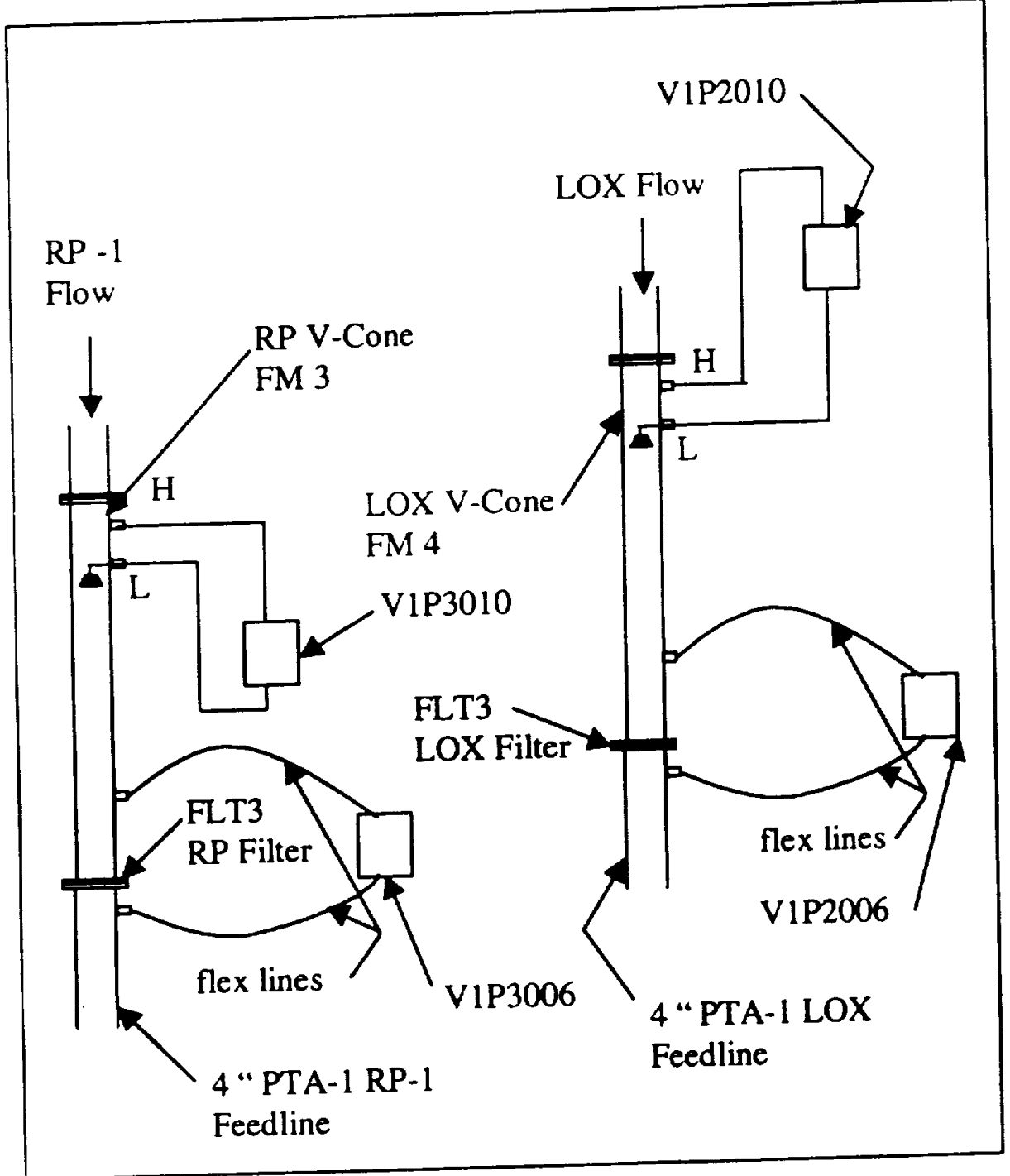

Figure 4

Initial PTA-I V-Cone Flowmeter

Configuration 
Initial Facility Configuration (continued)

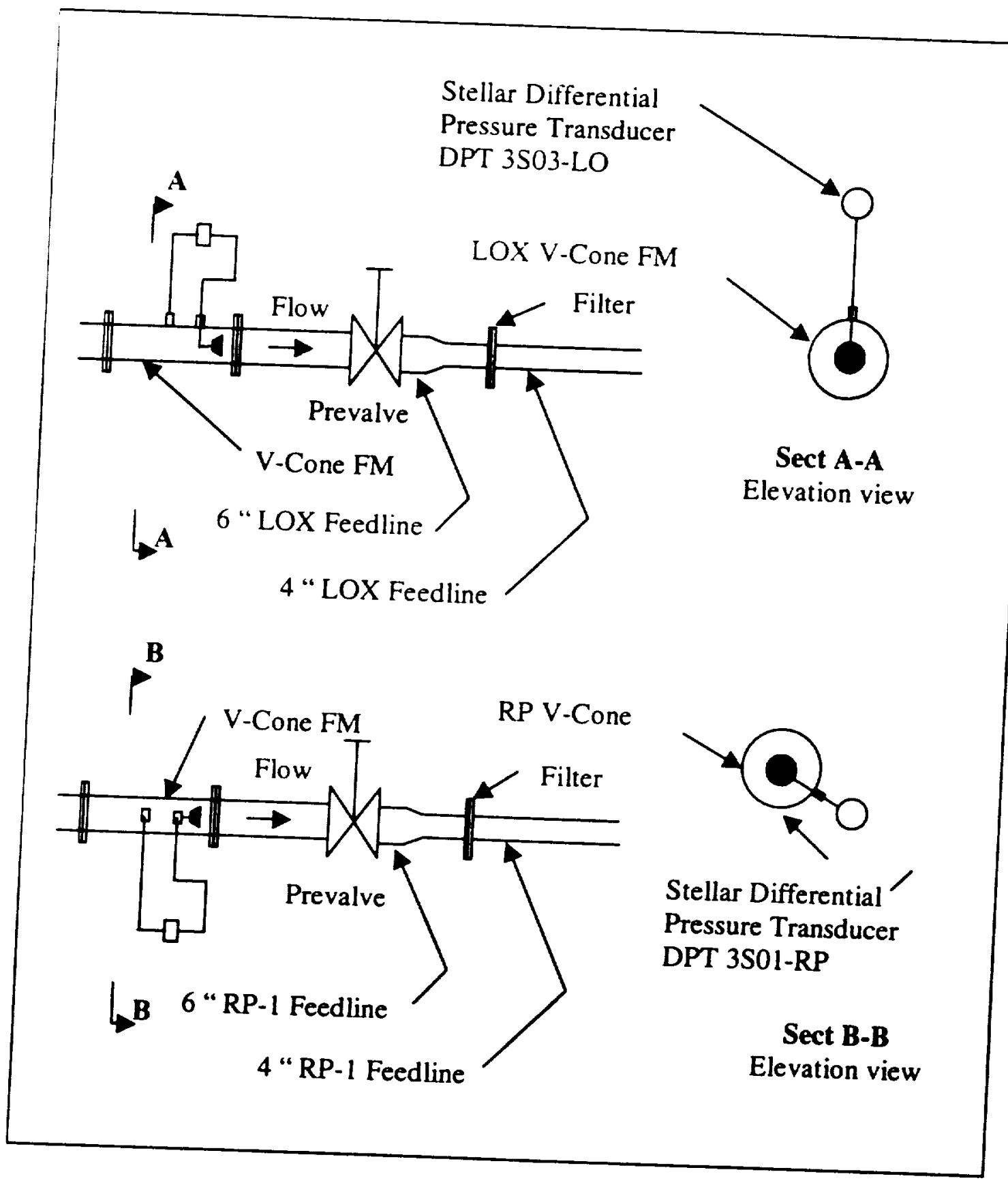

Figure 5

Initial HTF V-Cone Flowmeter

Configuration 


\section{INVESTIGATION}

The approach chosen for evaluating measurement techniques was to run a series of cold flow tests in both LOX and RP-1. Several tests were conducted to identify and resolve the oscillations seen in the $\mathrm{V}$-Cone flow meter data. The team decided that if the oscillations could be removed by filtering (either electrically or mechanically) without compromising the resulting steady-state flowrate data, then their objective would be met. There were two approaches to filtering the data that were assessed. The first approach was to install mechanical filters (snubbers) in the sense lines. A snubber is a mechanical fitting that has porous material in the fluid flow path. The porous material in the snubber induces resistance to the fluid and results in lower oscillations in the data. Snubbers come in a variety of types depending on the expected density of the sensed fluid. The second approach was to replace the delta pressure transducer with one that had built-in electrical filtering (Rosemount transducer). It was decided to maintain the original measurement configuration (Stellar transducer without filtering) as well for comparison purposes. 


\section{LOX COLD FLOW TEST CONFIGURATION}

Instrumentation modifications to PTA-I flowmeter sense lines were implemented. For the first test, the PTA-1 LOX flowmeter was configured with a type EA snubber along with two additional delta pressure transducers [3] as shown in figure 6. A type EA snubber is designed for vapor.

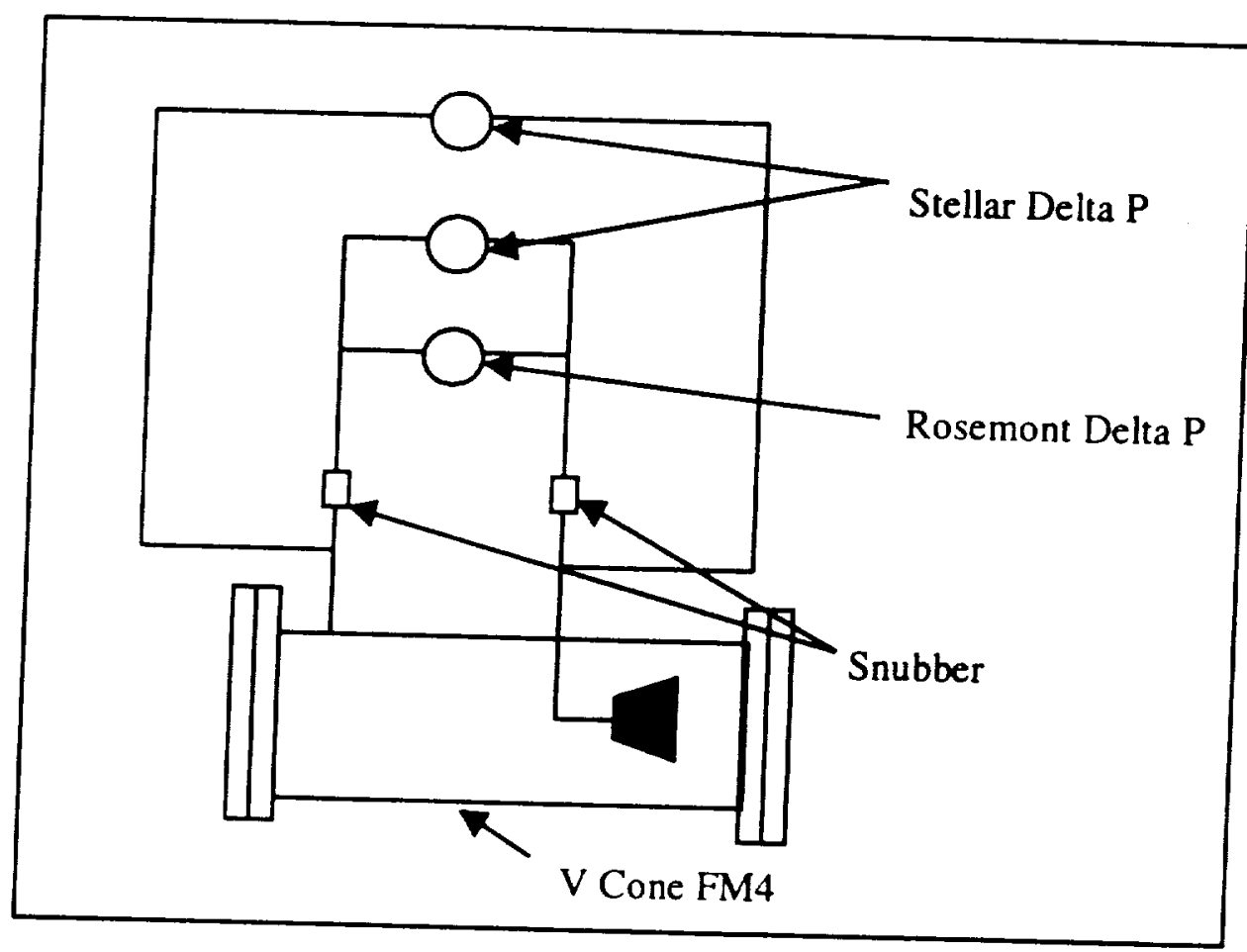

Figure 6

PTA-1 LOX Flowmeter

Configuration 


\section{LOX COLD FLOW TEST RESULTS}

The results for the LOX cold flow test [1] are shown in Figure 7 below. Both the Rosemount and the Stellar delta pressure transducers configured with type EA snubbers provided acceptable oscillation levels. The transient response of the Rosemount transducer showed about a 200 millisecond lag. As shown in Figure 8, both measurements showed good agreement with each other and with the flowrate calculated by tank level measurements [4].

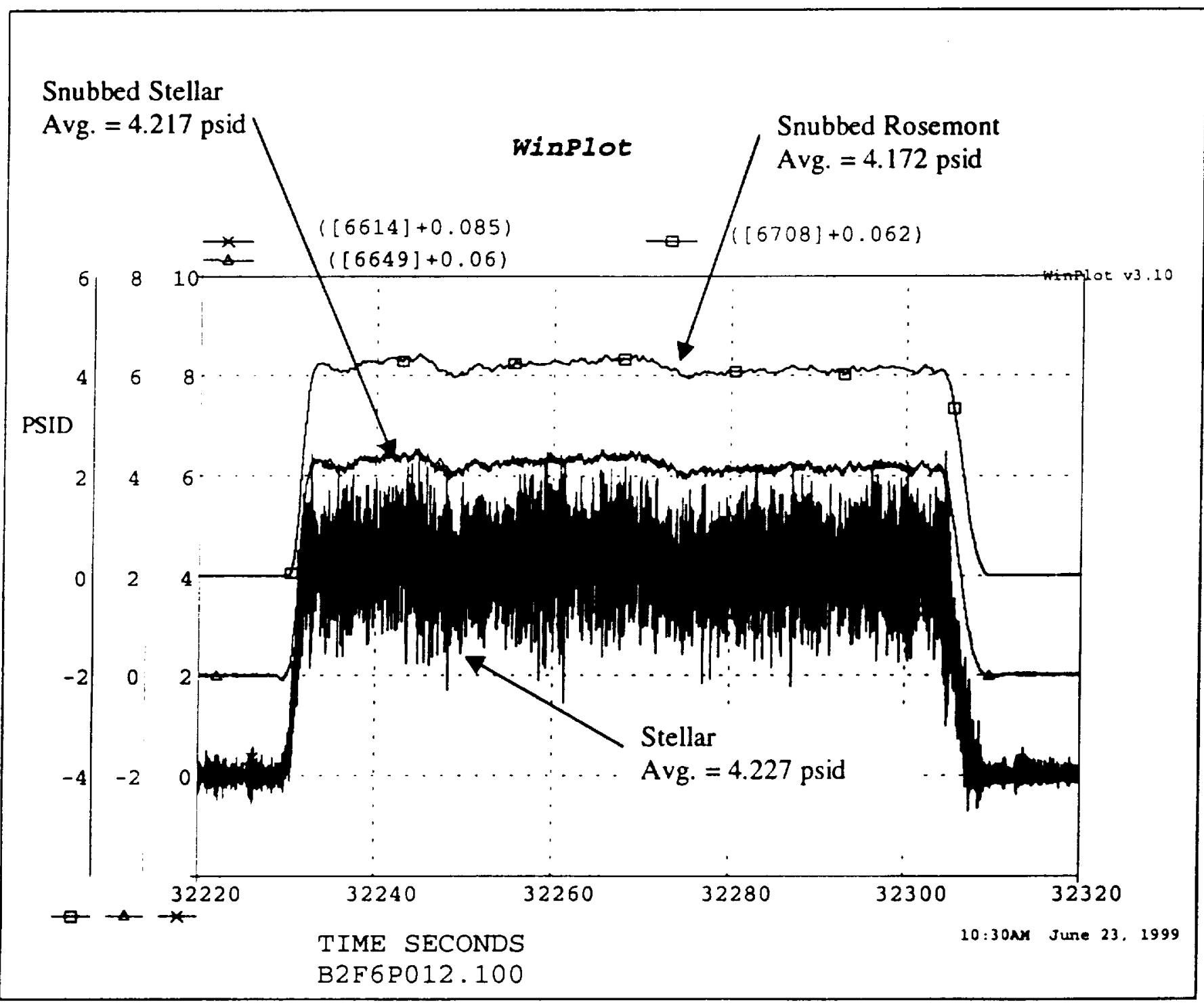

Figure 7 
LOX Cold Flow Test Results (continued)

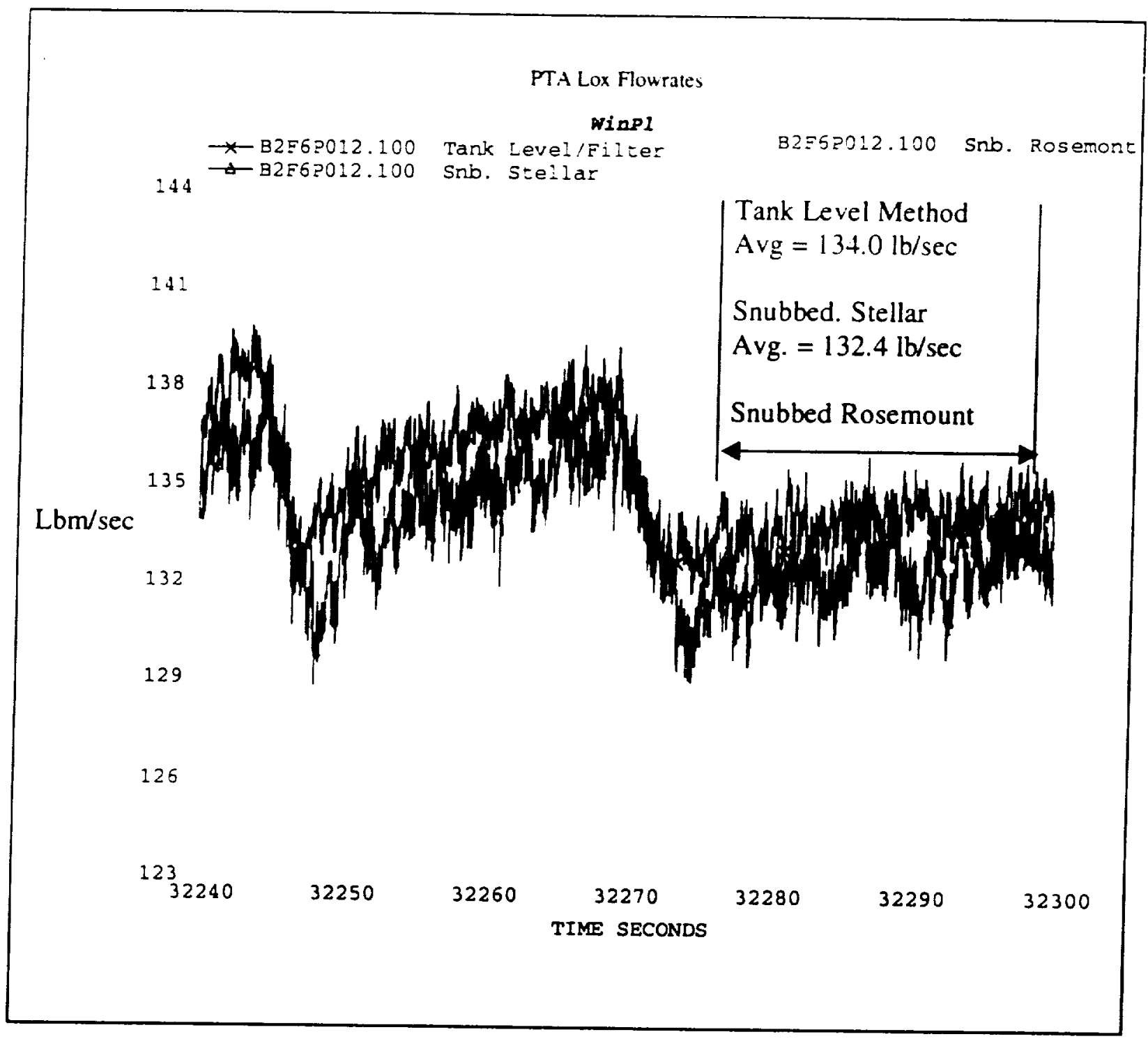

Figure 8

Comparison of Measured LOX

Flow Rates 


\section{RP-1 COLD FLOW TEST CONFIGLRATION}

The RP-1 flowmeter data resolution proved more challenging. The initial test on PTA-1 did not provide acceptable results with any of the measurements used. Due to facility constraints, the cold flow testing was moved to HTF. The HTF RP-I V-Cone validation tests 1 through 4 were conducted with different types of snubbers, sense line routing. and delta pressure transducer configurations $[5,6.7]$. The delta pressure measurement on the filter was also used to evaluate measurement configurations. In addition, a turbine type flowmeter was installed to verify the results since the tank level gages on this facility were not as accurate. Figure 9 shows the configuration of validation test 1 . The testing procedure and configuration for validation tests 1 through 4 are in appendix $A$.

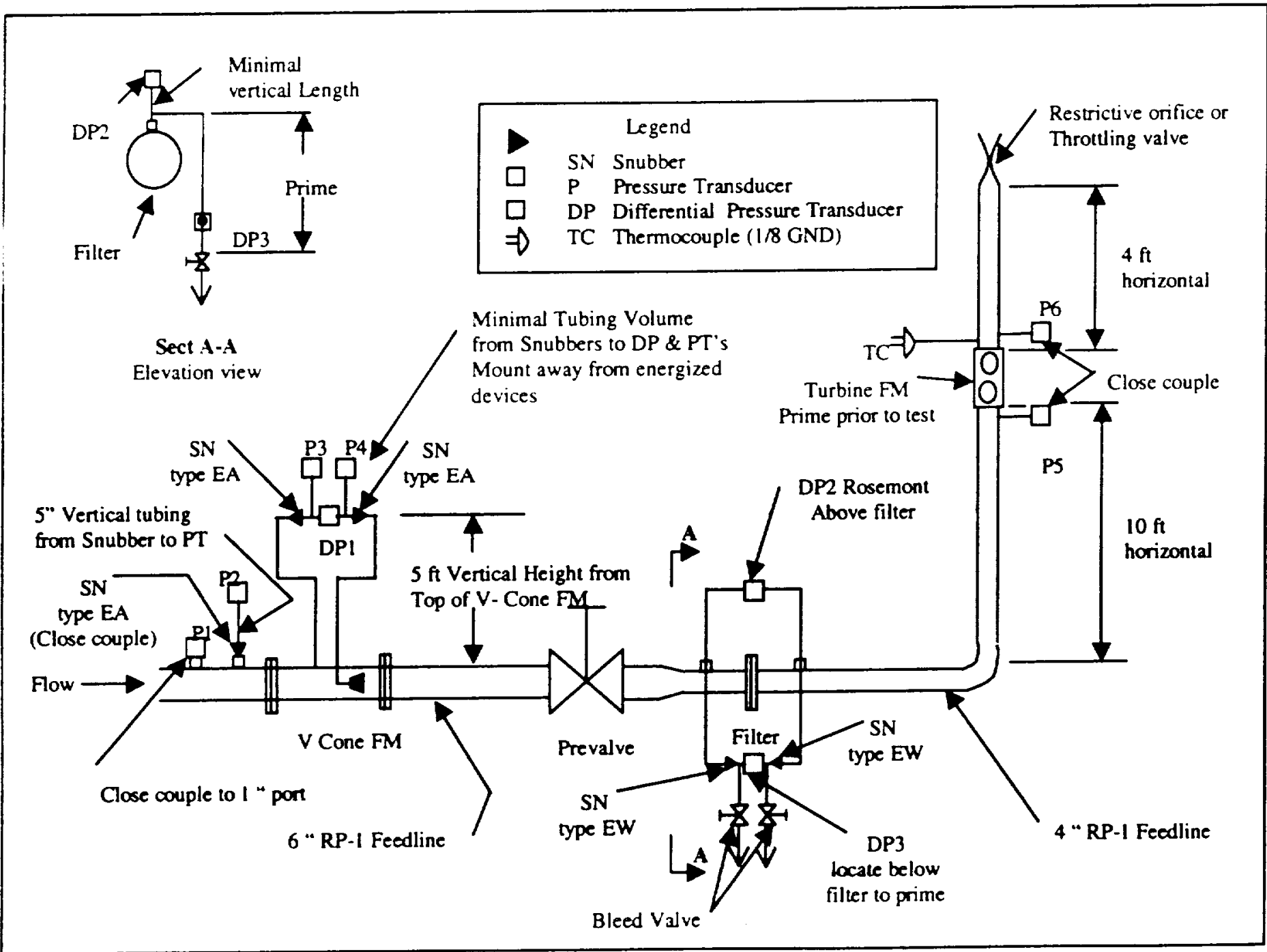

Figure 9 


\section{RP-1 COLD FLOW TEST RESULTS}

The initial RP-1 cold flow test conducted on PTA-1 utilized a Stellar pressure transducer with a type EA snubber. This configuration did not yeild reasonable delta pressure data. It is believed that this was due to two effects. First, there were differences in the RP-1 liquid levels in the upstream and downstream sides of the sense lines to the transducer. Although these differences in liquid levels were small, the magnitude of the measured delta pressure is small, so the change in elevation was significant. Secondly, it is believed that RP-1 reached the snubbers and wetted the surface (the snubbers installed were not designed for liquid flow). If the RP-1 wets the snubbers on the upstream and downstream side of the delta pressure measurement differently, it effects the resistance in the sense line and the resulting measured pressure. The following paragraphs summarize the test results. 


\section{TESTING RESULTS WITH STELLAR TRANSDUCERS}

A Stellar delta pressure transducer configured with type EA snubber on the V-Cone flowmeter was used on HTF RP-I V-Cone Validation Test 1[5]. This was the configuration that was used on the PTA-1 cold flow test for both the LOX and the RP-1 $V$-Cone flowmeters. The oscillation levels using the type EA snubters were greatly reduced, however unrealistic data was observed after the first flow test. The test was run at several different tank pressure settings. Data from the first pressure setting as shown in Figure 10 shows that transient flow rate changes tracked the turbine flow meter data.

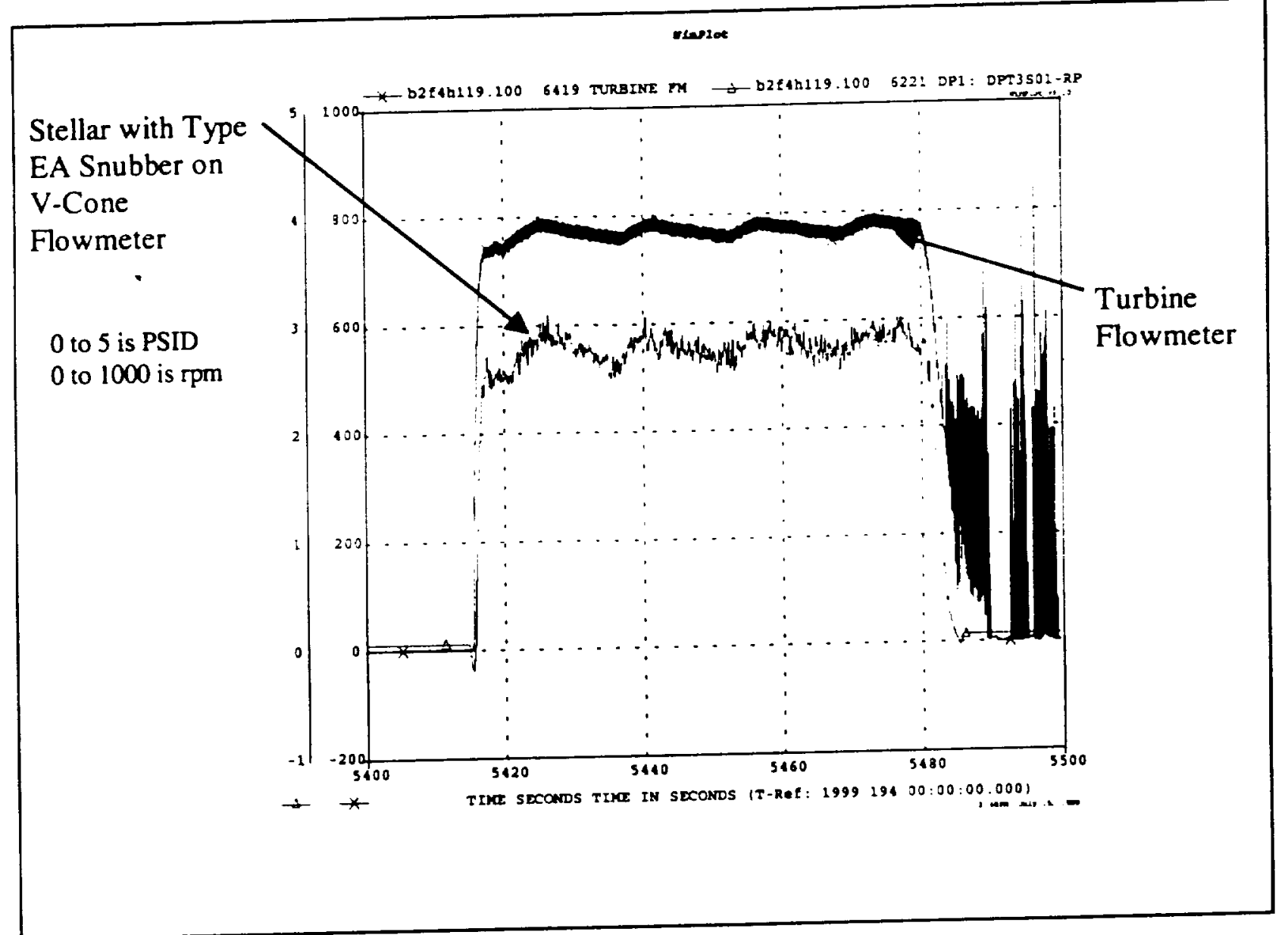

Figure 10

HTF Test 1 First Pressure Setting 
Testing Results with Stellar Transducers (continued)

The delta pressure data from the third pressure setting did not track the turbine flowmeter data [5] as shown in Figure 11. The sense lines were also observed to hold pressure after the test system was vented. Data analysis showed that the test set up allowed for a partial vacuum (2 PSIA) to be induced on the snubbers between pressure settings which during the next pressure cycle forced RP-1 into the sense line. The type EA snubbers were inspected after the test and were verified to be wet with RP-1.

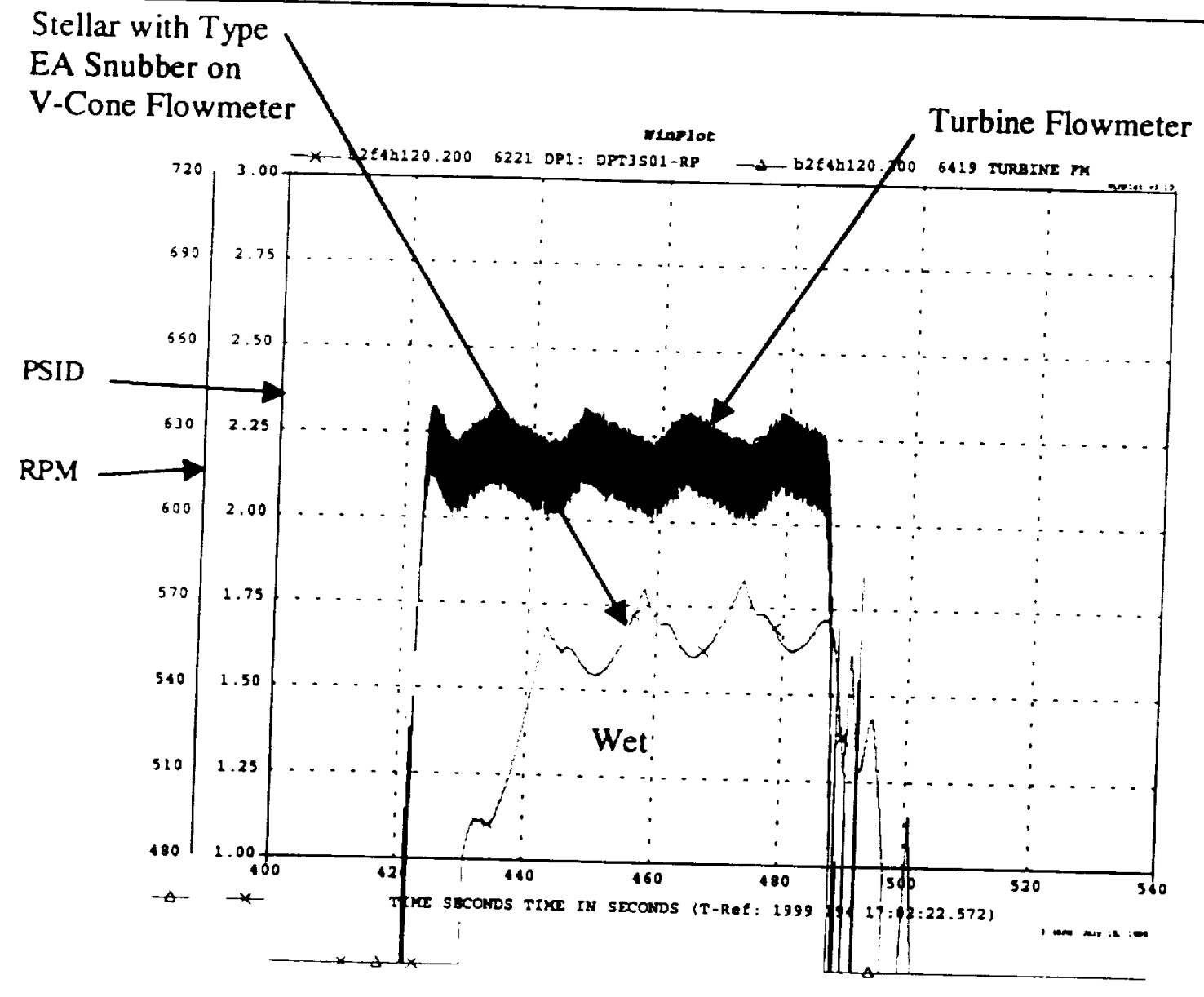

Figure 11

HTF Test 1 Third Pressure Setting 


\section{Testing Results with Stellar Transducers (continued)}

A Stellar delta pressure transducer configured with type EW snubter was used on the filter for the HTF RP-1 V-Cone Validation Tests 1 and 2. A type EW snubber is designed for water. The filter snubbers vere primed to ensure that they were wet with RP-1. The oscillation levels using the EW snubbers [5] were again reduced. however poor and inconsistent transient response was observed in the data. The inconsistent data from HTF RP-1 V-Cone Validation Tests 1 and 2 is shown in figures 12 and 13.

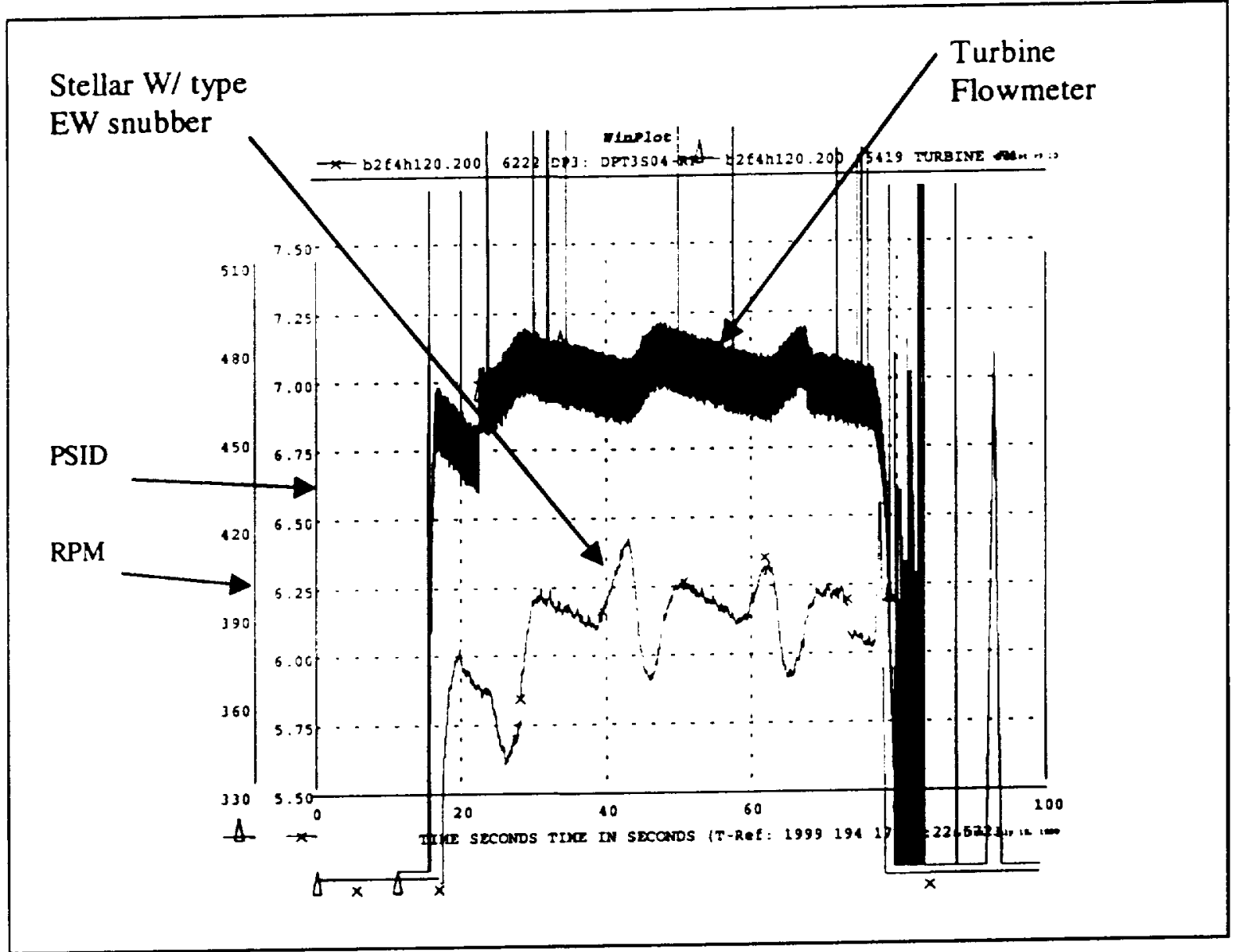

Figure 12

HTF RP-1 V-Cone Validation Tests 1

Poor Response of Filter Snubber 
Testing Results with Stellar Transducers (continued)

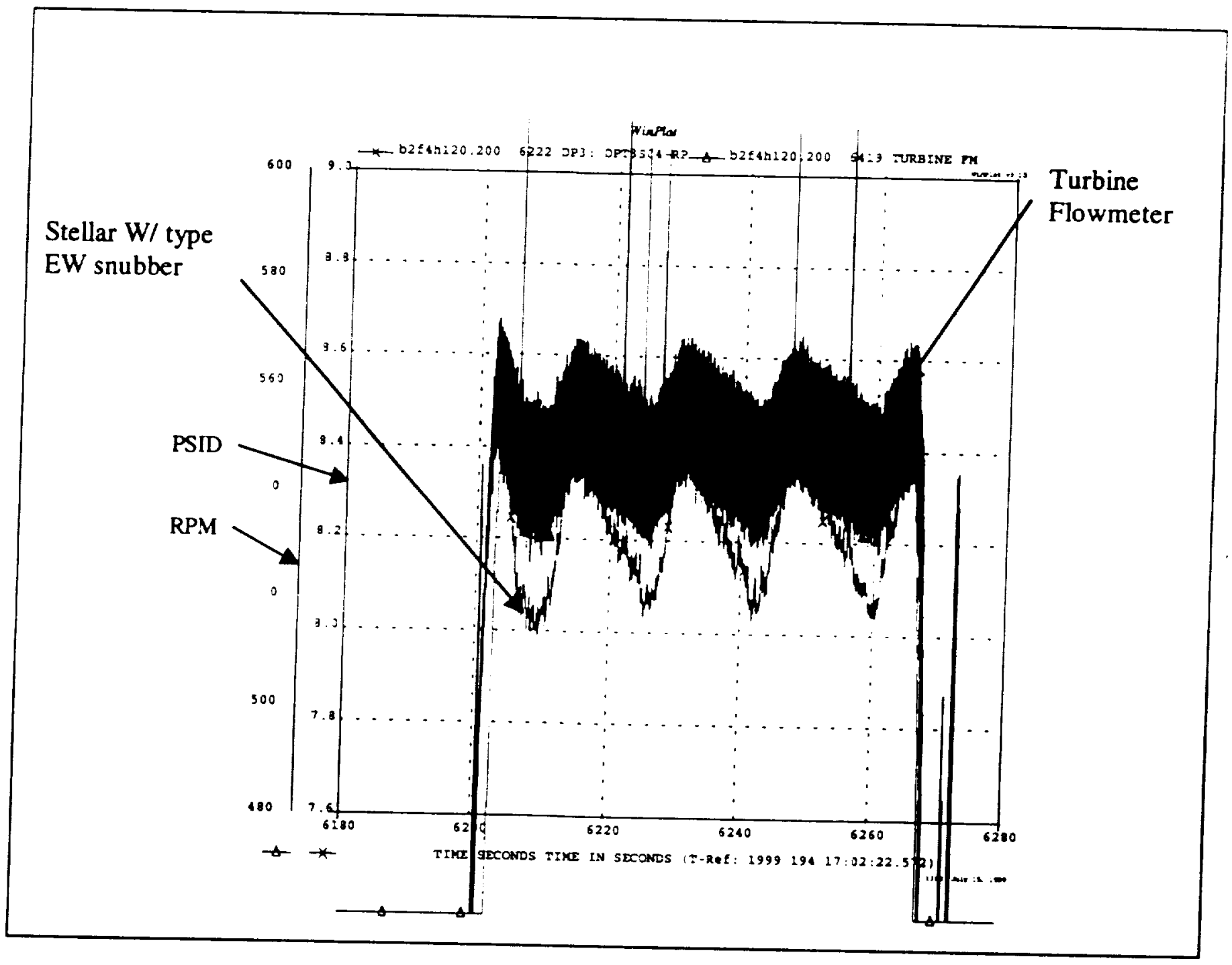

Figure 13

HTF RP-1 V-Cone Validation Tests 2

Good Response of Filter Snubber 
Testing Results with Stellar Transducers (continued)

A Stellar delta pressure transducer configured with type EL snubher was used on the filter for the HTF RP-I V-Cone Validation Tests 3 and 4. A lype EL snubber is designed for light oil. These filter snubbers were also primed to ensure that they were wet with RP-1. The oscillation levels in type EL snubbers [7] shown in figure 14 are around 0.2 PSID which is less than the unsnubbed configuration.

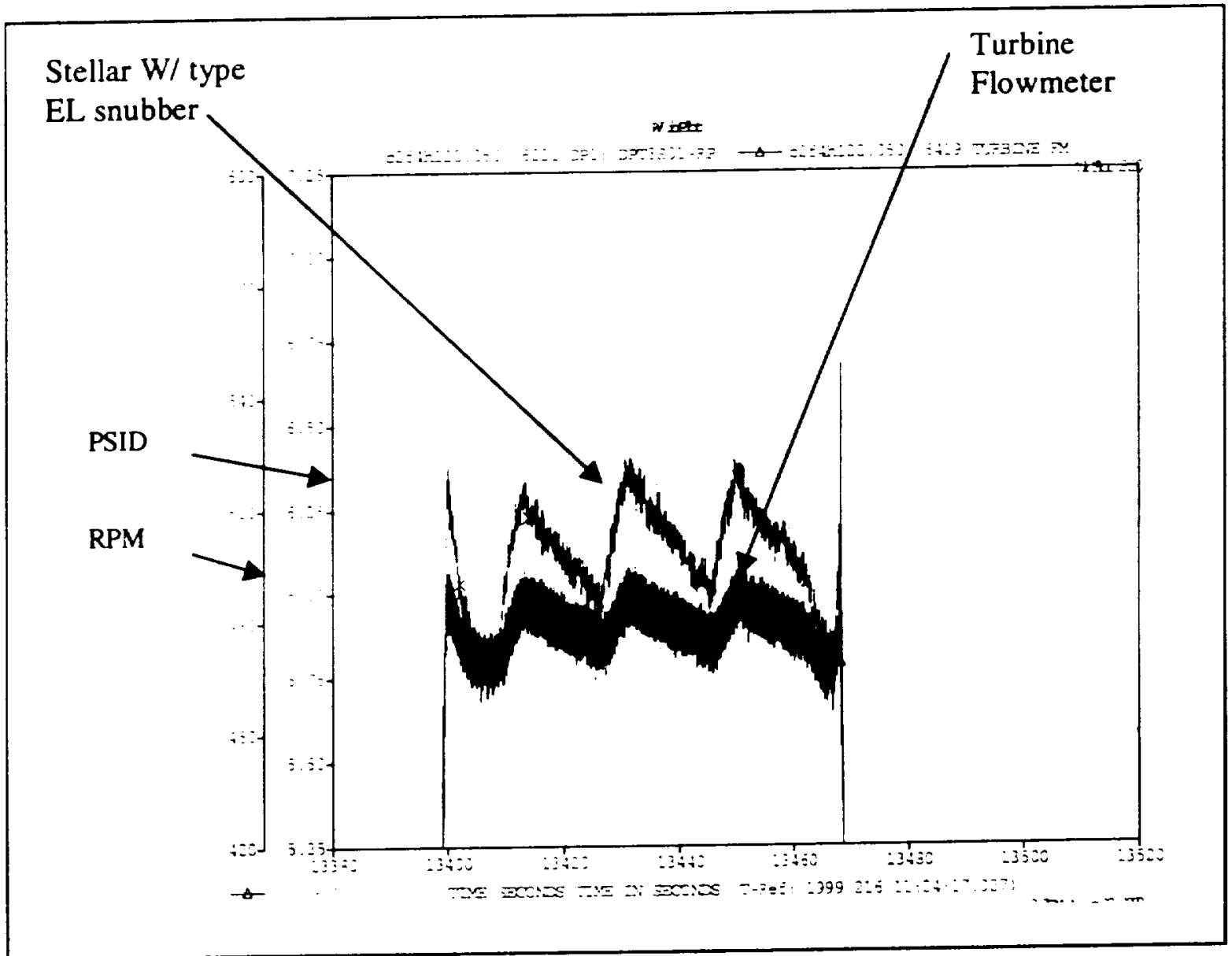

Figure 14

Filter Snubber on HTF RP-1 V-Cone

Validation Test 4 
Testing Results with Stellar Transducers (continued)

A Stellar delta pressure traniducer configured with type EH snubber was used on the VCone flowmeter for the HTF RP.1 V-Cone Validation Tests 3 and 4 . A type EH snubber is designed for heavy oil. These snubbers were again primed to ensure that they were wet with RP-1. The oscillation levels [7] observed were around 0.2 PSID which is similar to the oscillation level in a type EL snubber. The data from test 4 was used to calculate the turbine and V-Cone flowmeter flow rate and is shown in Figure 15. The transient response is masked by the oscillation level.

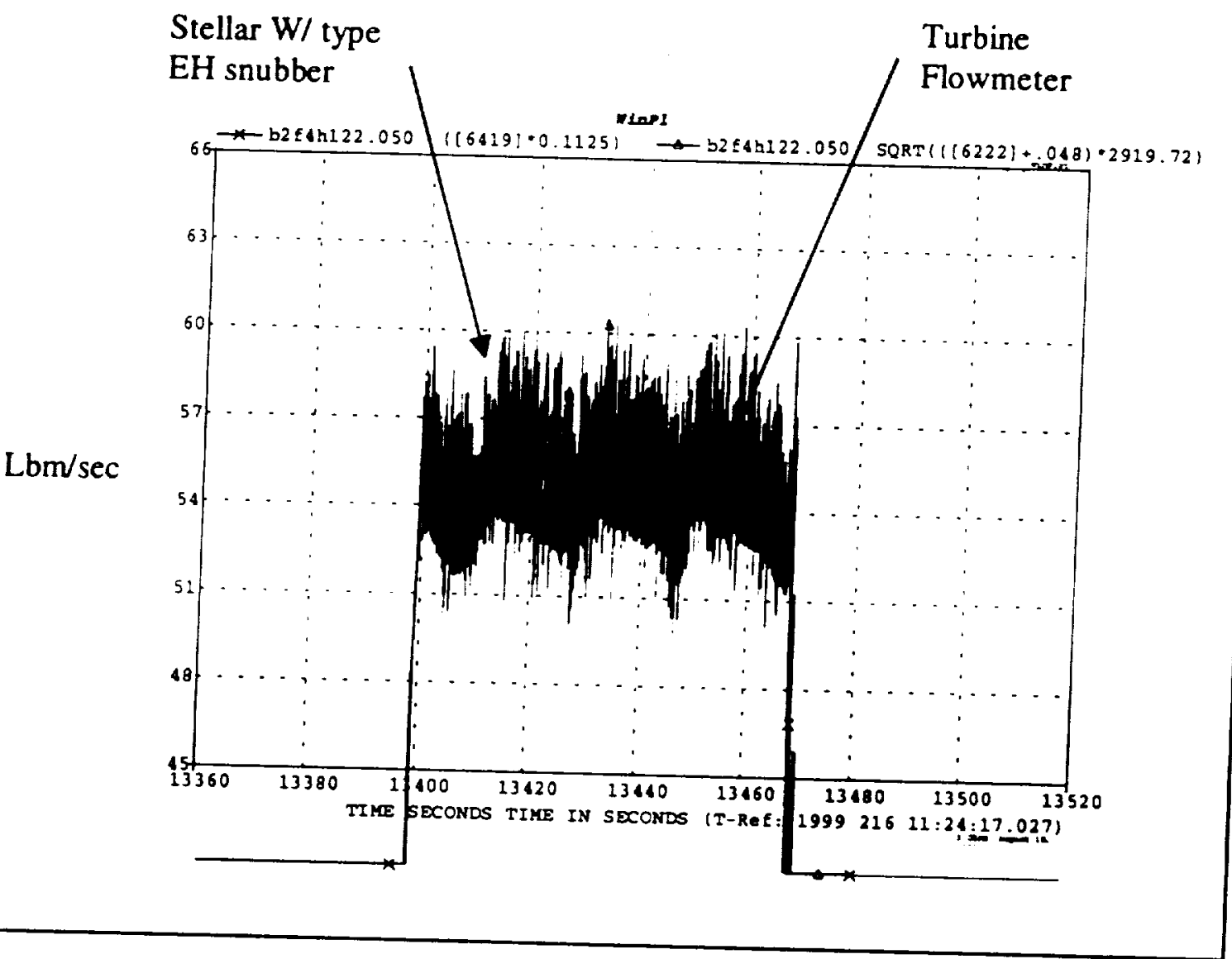

Figure 15

Calculated Flow Rate Data 


\section{TESTING RESULTS WITH ROSEMOUNT TRANSDUCERS}

A Rosemount delta pressure transducer without a snubber was used on the RP-I filter during the HTF RP-1 V-Cone Validation Tests 1 \& 2. A Rosemount delta pressure transducer without a snubber was also used on the V-Cone flowmeter during HTF RP-1 V-Cone Validation Test $3 \& 4$. The oscillation level of the Rosemount delta pressure transducer without a snubber [6] was acceptable and is shown in figure 16. The caricature of the data follows turbine flowmeter data during pressure cycles of the RP-I run tank. The calculated flow rate from flow tests 3 and 4 show the $V$-Cone flowmeter flow rate within $2 \mathrm{lbm} / \mathrm{sec}$ of turbine flowmeter flow rate.

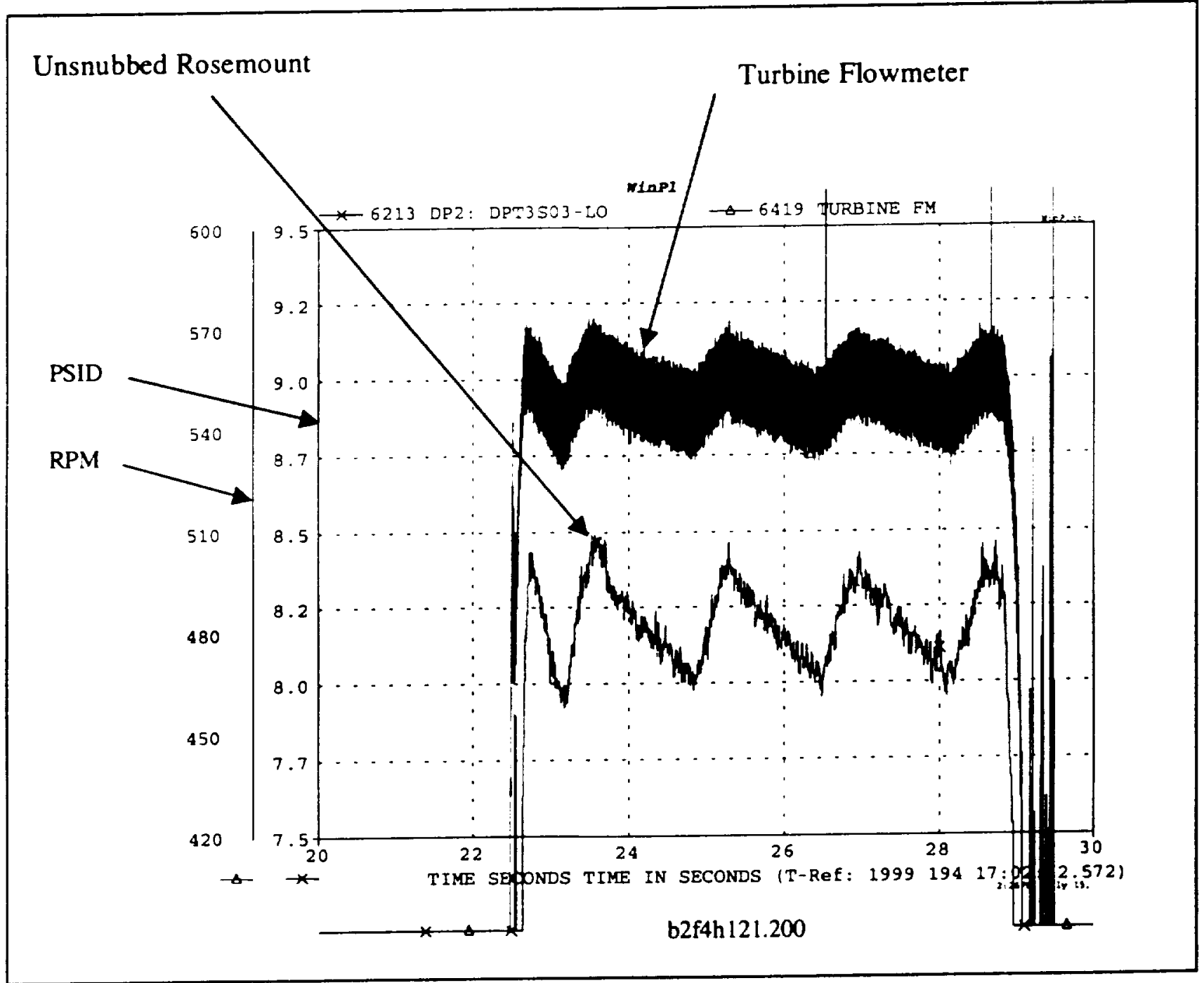

Figure 16

Rosemount Delta Pressure Transducer

Oscillation Level 
Testing Results with Rosemount Transducers (continued)

There was one issue discovered with the Rosemount transducer however. In the HTF RP-I V-Cone Validation Test 3, a Rosemount delta pressure transducer without a snubber was mounted above the V-Cone flowmeter. A type EH snubber was used on a Stellar delta pressure transducer mounted below the flowmeter. The type EH snubber, which is designed for heavy oils, was primed with RP-1 prior to the flow test. Figure 17 shows good correlation between the two delta pressure transducers [6], however there is a shift in the zero point of the transducer at line pressure changes.

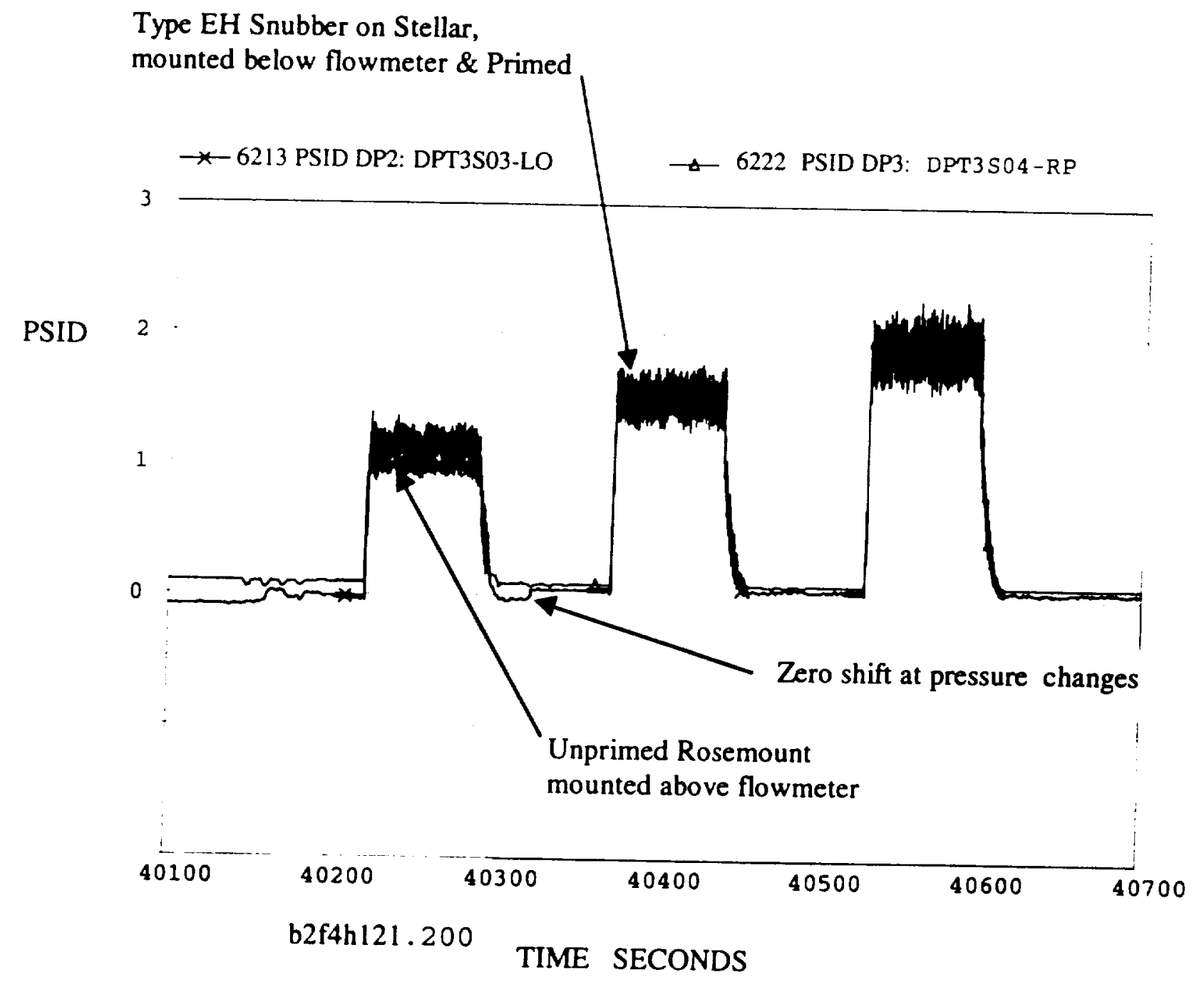

Figure 17

HTF RP-1 V-Cone Validation Test 3 
Testing Results with Rosemount Transducers (continued)

Figure 18 is a calculated zero-shift curve of the data $[6]$ in figure 17 above. A very unusual zero-shift curve was observed that has been attributed to elevation effects in sense lines.

The sense lines were about ten feet in length and the unsnubbed Rosemount was about seven feet above the V-Cone flowmeter.

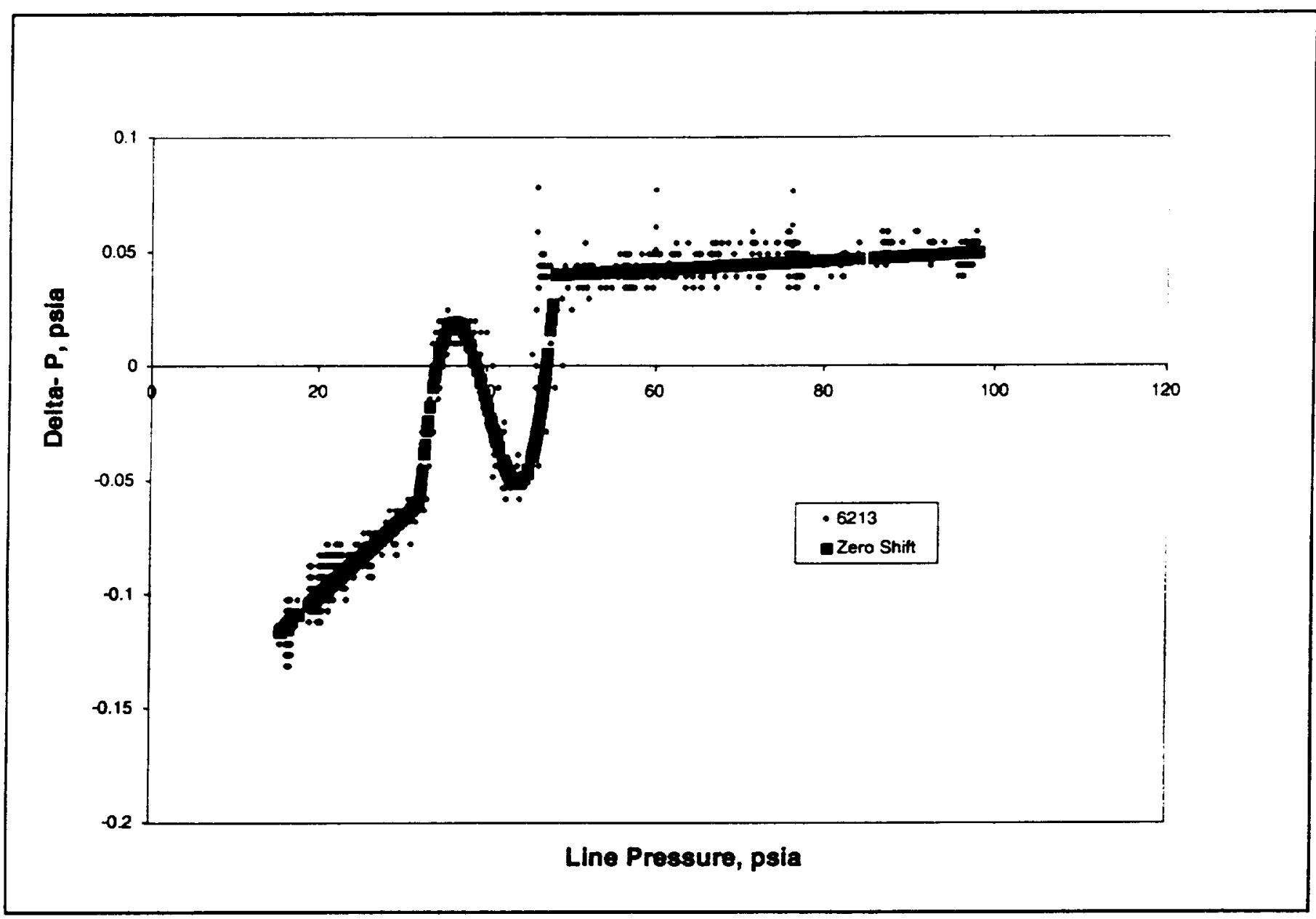

Figure 18

Rosemount Zero Shift Data 
Testing Results with Rosemount Transducers (continued)

The HTF RP-I V-Cone Validation Tests 4 used an un inubbed Rosemount and a type EH snubber on a Stellar delta pressure transducer, with both transducers mounted belo:v the V-Cone flowmeter. The sense lines were short and primed with RP-1. Figure 19 shou's less zero-shift with line pressure for the Rosemount transducer [7]. A greater data oscillation was observed using the type EH snubber compared to the type EL snubber.

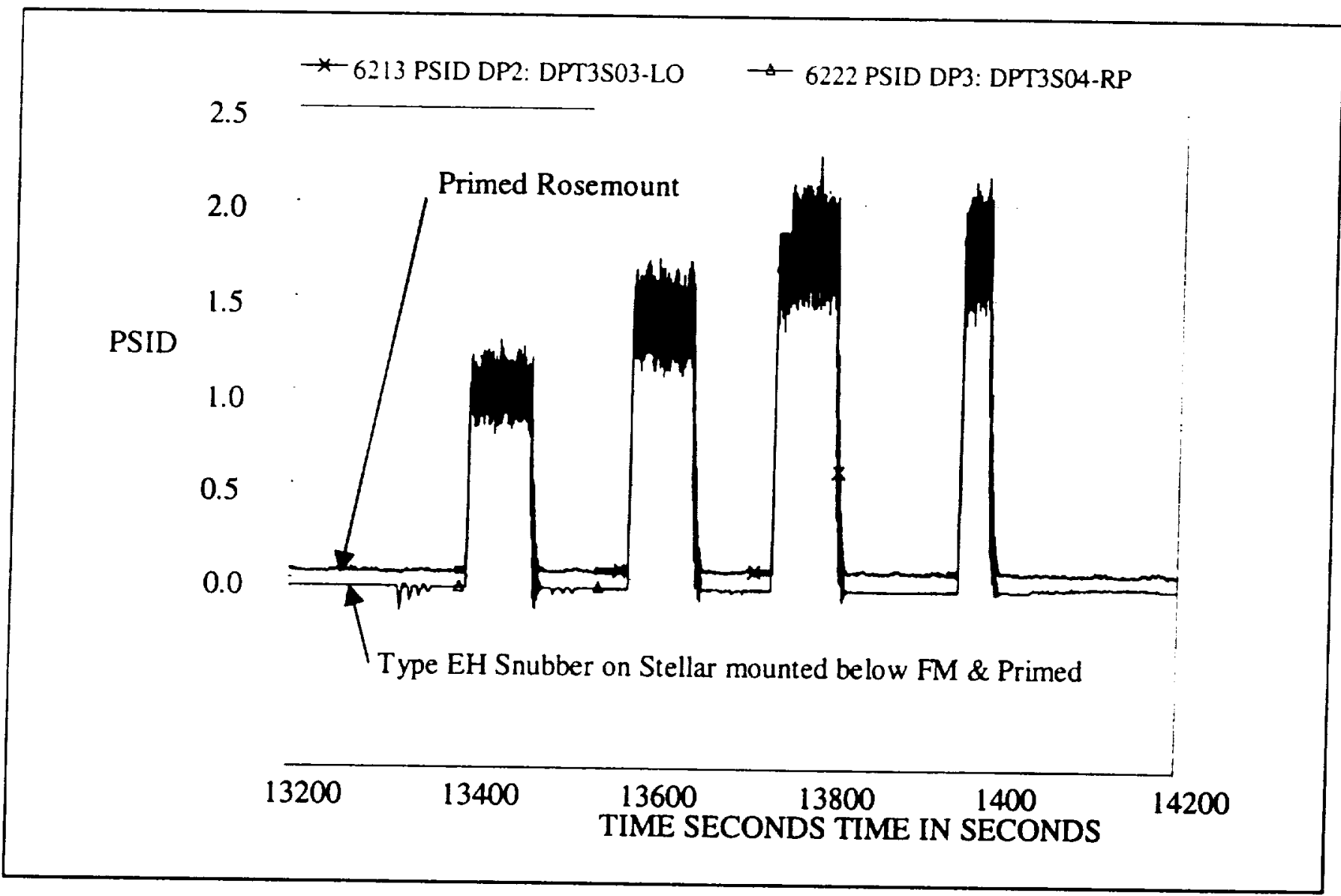

Figure 19

The HTF RP-1 V-Cone Validation Test 4 
Testing Results with Rosemount Transducers (continued)

Figure 20 shows that the calculated zero-shift curve [7] is less erratic with the sense lines shortened and primed in the HTF RP-1 V-Cone Validation Test 4 . As a result of the configuration change from the previous test, the calculated $V$-Cone flowmeter flow rate[7] shown in figure 21 matched the turbine flowmeter flowrate to within $2 \mathrm{lbm} / \mathrm{sec}$.

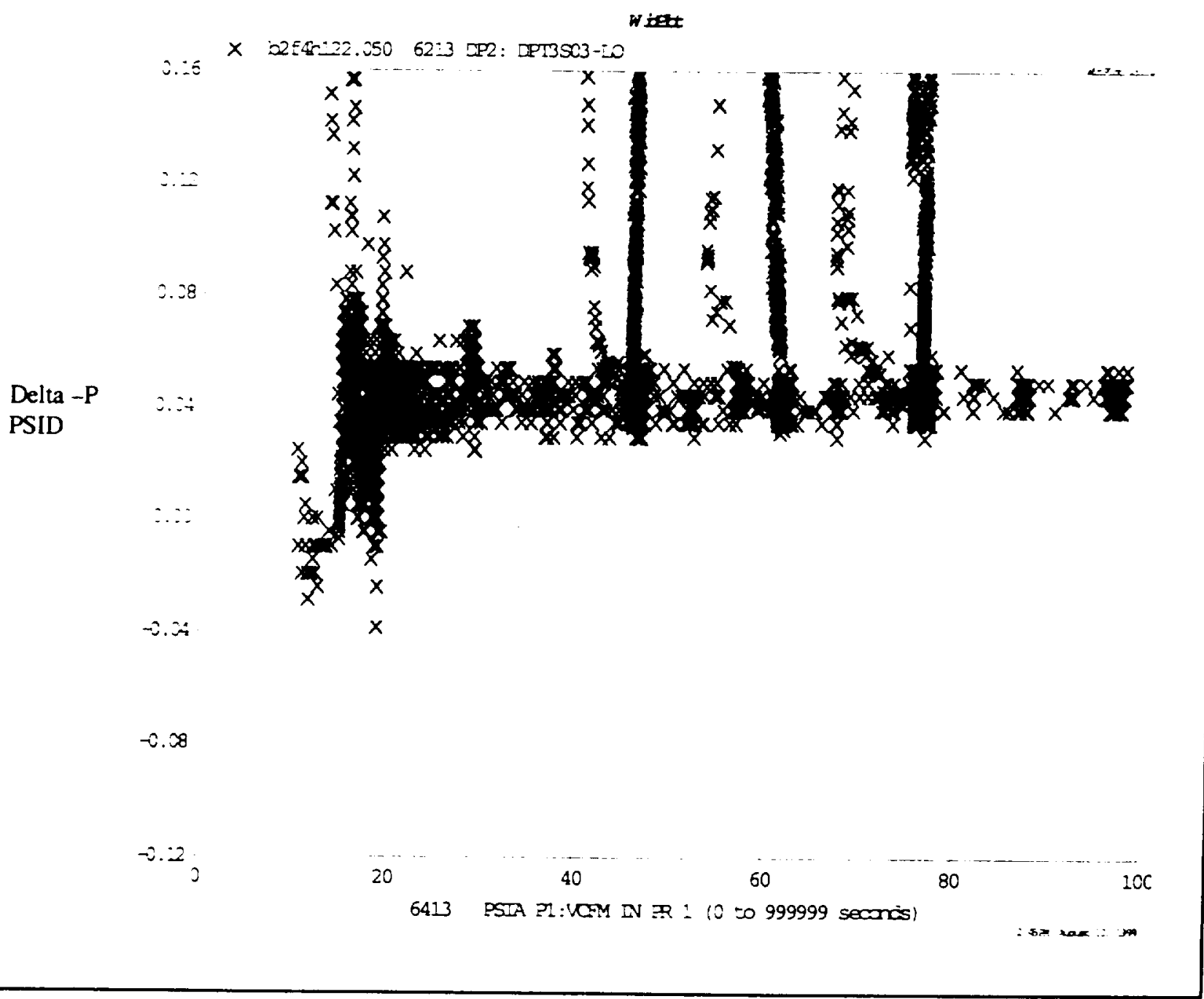

Figure 20

Zero-Shift Curve 
Testing Results with Rosemount Transducers (continued)

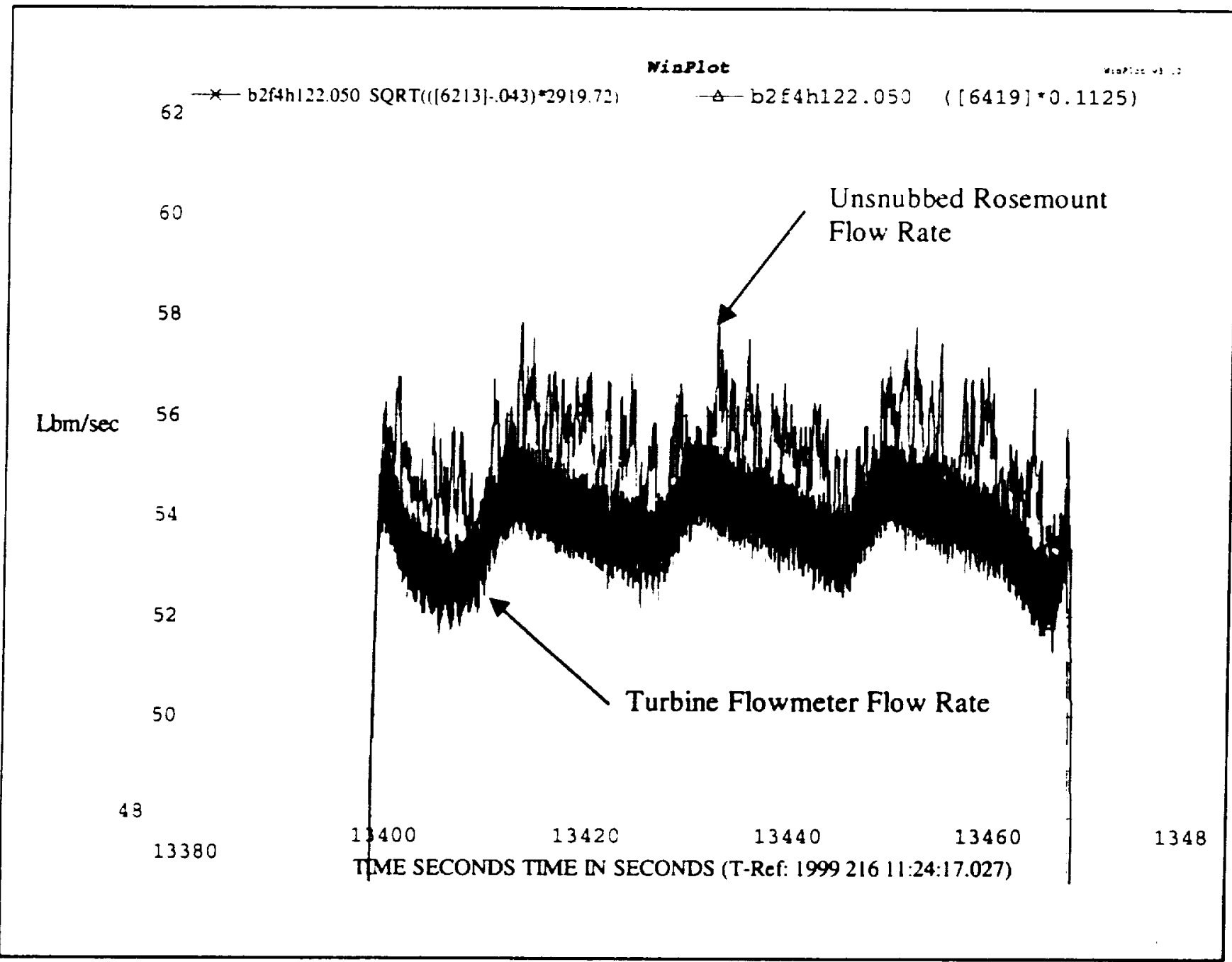

Figure 21

V-Cone and Turbine Flowmeter Flow Rates 


\section{CONFIGURATION SUMMARY}

A summary of the results from the flow tests conducted $[4,5,6,7,8]$ is summarized in table 2 below.

Table 2 Test Results Summary

\begin{tabular}{|l|l|}
\hline Delta Pressure Transducer Configuration & Data Results \\
\hline Stellar with out snubber & Excessive oscillation level \\
\hline Rosemount with out snubber & $\begin{array}{l}\text { Low oscillation level, priming with RP-1 } \\
\text { reduces zero-shift with line pressure changes. }\end{array}$ \\
\hline Stellar with EA snubber & $\begin{array}{l}\text { Low oscillation level in LOX sysiem when } \\
\text { sensor is ambient temperature. } \\
\text { Unacceptable response when wet with RP-1. }\end{array}$ \\
\hline Stellar with EW snubber & $\begin{array}{l}\text { Inconsistent transient response. } \\
\text { Moderate oscillation level. }\end{array}$ \\
\hline Stellar with EL snubber & $\begin{array}{l}\text { Moderate oscillation level. } \\
\text { Must be primed for RP-1. }\end{array}$ \\
\hline Stellar with EH snubber & $\begin{array}{l}\text { High oscillation level. } \\
\text { Must be primed for RP-1. }\end{array}$ \\
\hline Rosemount with EA snubber & $\begin{array}{l}\text { Low oscillation level in LOX system when } \\
\text { sensor is ambient temperature. } \\
\text { Unacceptable response when wet with RP-1. }\end{array}$ \\
\hline
\end{tabular}




\section{RECOMMENDATIONS}

Based on the series of tests conducted during the investigation, the flowmeter team has several recommendations. For measurement of RP-1 flowrate, the delta pressure should use an unsnubbed Rosemount sensor. The sense lines should be short, with no changes in elevation between V-Cone taps and sensor. In addition, the sense lines should be primed to eliminate any possible issues with fluid liquid level. Because of the very low delta-P's measured during normal flow, it very important to attempt to remove all error sources. Elevation effects in RP- 1 sense lines can be significant if not eliminated. It is also important to be able to understand that sensor biases can change with pressure. It is therefore recommended to pressurize to run pressures slowly, if possible, so that a curve of delta pressure vs. absolute pressure can be generated under no-flow conditions. The flowmeter team recommendation for LOX V-Cones is to use a Stellar sensor with EA snubbers. The lines should be oriented such that the snubbers and sensor are slightly above the V-Cone taps. The lines should also be long enough to assure GOX is in the sense line on both sides of each snubber.

Figure 22 shows the recommended RP-1 configuration for the PTA-1 Flowmeter sense lines. Figure 23 shows the recommended RP-1 configuration for the HTF Flowmeter sense lines. 
Recommendations (continued)

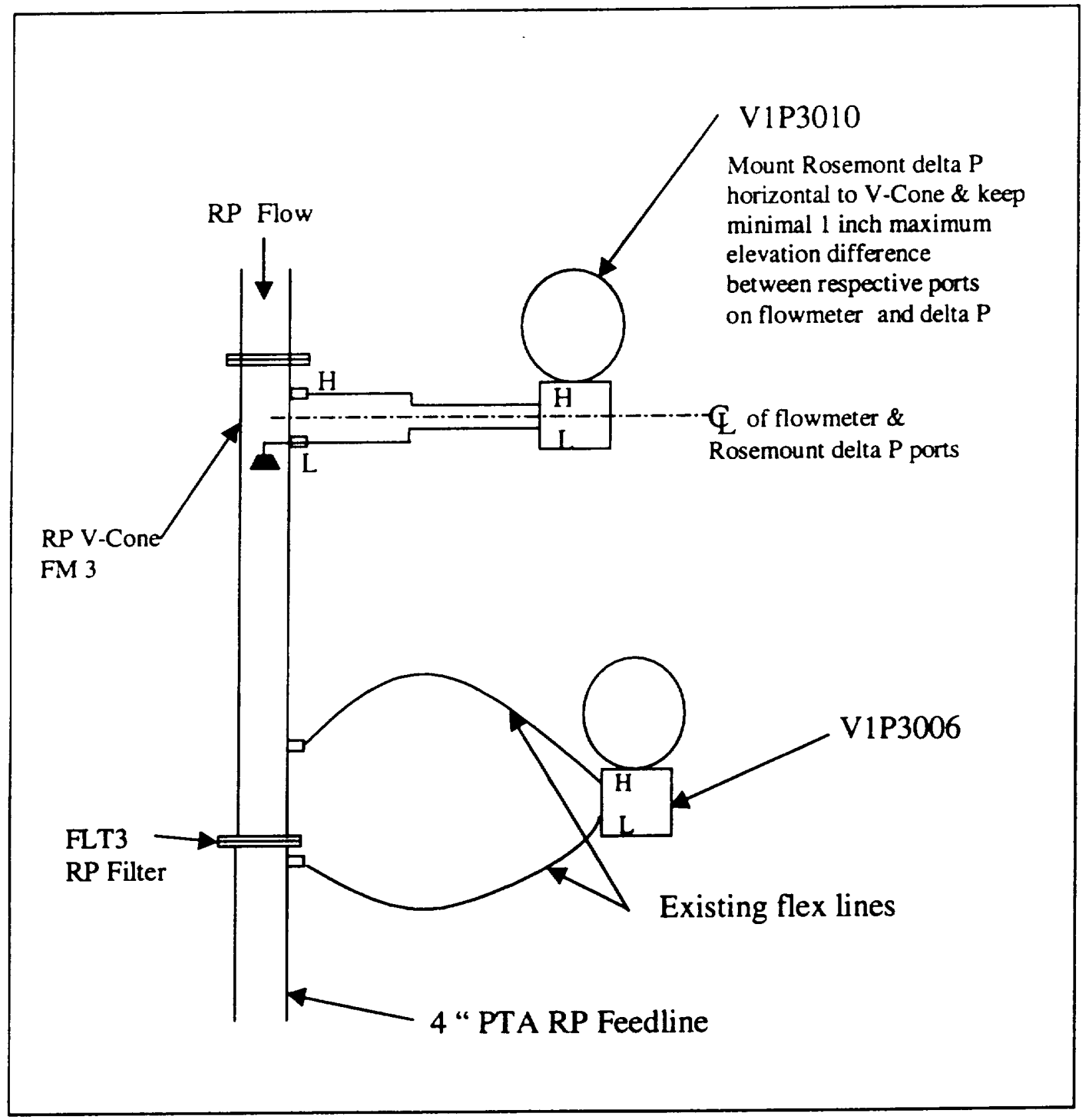

Figure 22

Recommended PTA-1 RP-1 Flowmeter Configuration 


\section{Recommendations (continued)}

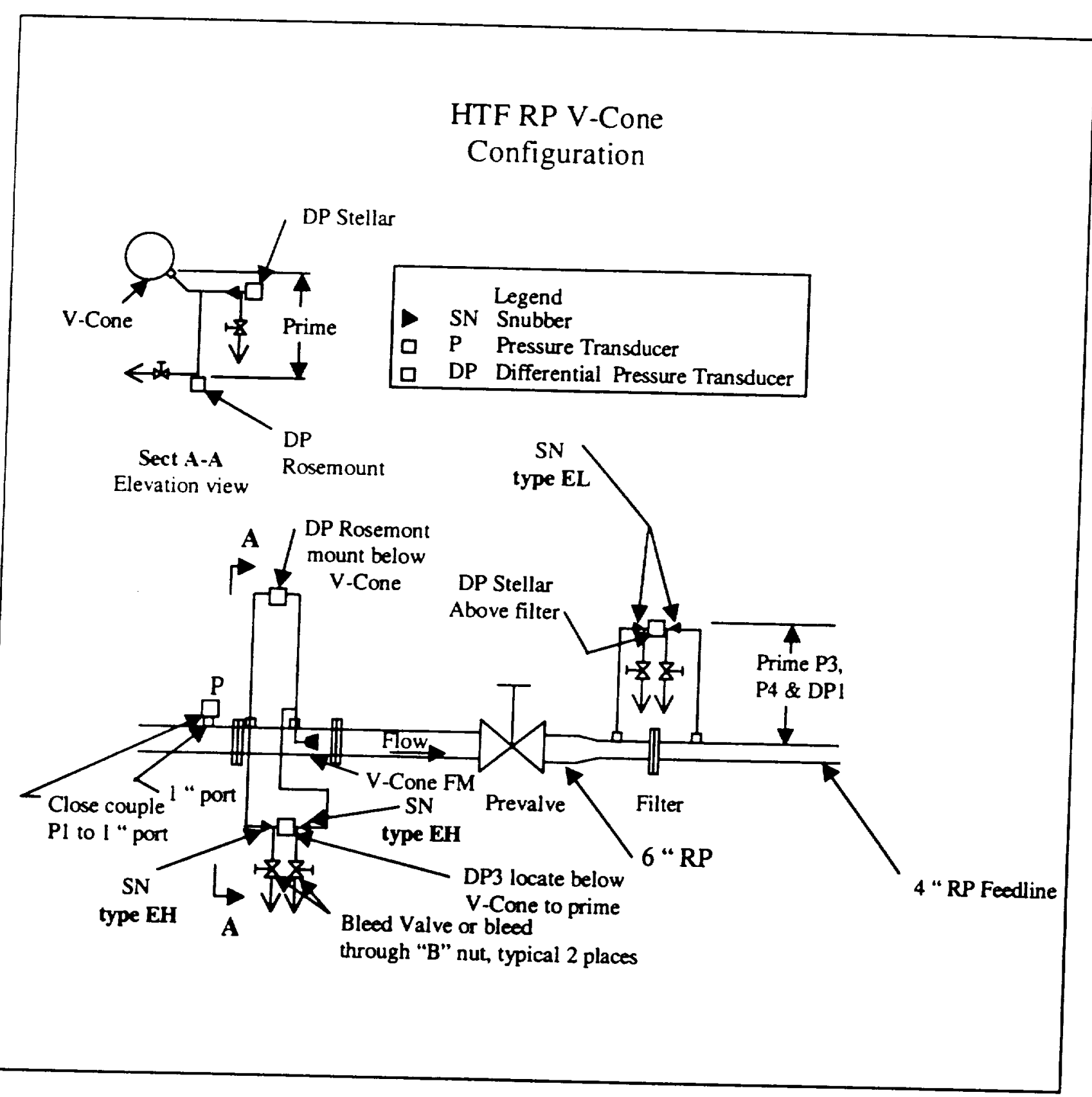

Figure 23

Recommended HTF RP-I Flowmeter Configuration 


\section{REFERENCES}

1. Data is from various tests conducted at SSC from 5/25/1999 through 6/22/1999 to verify requirements of the "Low Cost Technologies Propulsion Test Article \#1 Test and Checkout Requirements Document," MSFC-SPEC-2760, March 2, 1999.

2. Data is from the Fastrac engine test conducted at SSC on $5 / 14 / 1999$ per Test Request "H2b-2 GGFV Orifice Gains Test \#l," Test Number 0910-022-9134-HTF, 5/14/1999.

3. "PTA1 Snubber Addition," ES\# 265, 6/16/1999.

4. Data is from test conducted at SSC on 6/22/1999 per "LOX And RP Tanking Test," TPS-BBM-324, 6/22/1999.

5. "RP Flow Test with Turbine Flowmeter on HTF Setup," MSFC Engineering Sheet ES\# 270, 6/30/1999.

6. "HTF RP V-Cone Validation Test 3 Configuration," MSFC Engineering Sheet ES\# 282, 7/16/1999.

7. "HTF RP V-Cone Validation Test 4," MSFC Engineering Sheet ES\# 289, 7/30/1999.

8. "PTA RP And LOX Flowmeter Delta P Configuration," MSFC Engineering Sheet ES\# 313, 8/16/1999. 


\section{APPENDIX A}

\section{HTF RP-1 V-CONE VALIDATION TEST PROCEDURE}


HTF RP V-Cone Validation Test

Pretest

Perform instrument verification for all added measurements per typical SSC verification procedures.

Verify Close-coupled PT at V-Cone inlet is on SDAS and hi-speed das.

Provide copies of SSC measurement verification procedures to MSFC.

Provide PID list with measurement locations indicated.

Provide capability to catch and accurately measure RP discharge if available.

Photograph in detail, using digital camera, all RP-1 feedline and sensors to be used in validation test to include the following:

-V-Cone, V-Cone delta pressure, static pressures, snubbers, senselines and thermocouple.

-Static pressures upstream of V-Cone, close coupled and snubbed with senselines.

-Filter Delta pressures (Stellar and Rosemount), snubbers, senselines and bleed valves.

-Piping installed for validation test from filter to engine orifice discharge.

-Turbine meter, upstream and downstream pressures and thermocouple

Transmit photographs to MSFC for inspection.

Verify Data on the Turbine Flowmeter by performing the following:

-With turbine meter connected and F/D powered "on" and in "operate" mode, record "zero" flow condition for 30 seconds using Low speed data system.

Ensure no flow, no purge or bleed and no valves cycled during operation. This is to characterize the base noise floor and F/D converter stability.

Without compromising signal grounding, input the following signals into the drag-on cable at the turbine meter: $100 \mathrm{HZ}, 200 \mathrm{HZ}, 300 \mathrm{HZ}, 400 \mathrm{HZ}$ and 500 $\mathrm{HZ}$ (all at $100 \mathrm{mV}$ amplitude)

Record each on high speed and low speed data systems. Use "XI pulse output" from the Trig tek 303A F/D to high speed and the "DC output" from F/D to Low speed. Record approximately 10 seconds for each input frequency.

Provide this data to MSFC. 


\section{Pretest (continued)}

Prime the turbine flowmeter prior to any pressurizing or flow operations. Ensure liquid at ALL TIMES to prevent damage to the turbine meter.

Prime/Bleed both sides of the filter DP senselines to ensure pure RP- 1 and no gas present at the snubber and DP. (i.e. ensure the senselines are full of RP up to the DP sensor)

\section{Test 1}

Fill RP run tank to 2800 gallons minimum.

Turn the SDAS on slow speed.

Pressurize run tank to 40 PSIA.

Switch SDAS to fast speed and start Hi-Speed DAS (HSD).

Open Prevalve slowly.

Flow for 60 seconds

Close Prevalve slowly.

Switch SDAS to slow speed and HSD off.

Pressurize run tank to 55 PSIA.

Switch SDAS to fast speed and HSD on.

Open Prevalve slowly.

Flow for 60 seconds

Close Prevalve slowly.

Switch to SDAS to slow speed and HSD off.

Pressurize run tank to 70 PSIA

Switch SDAS to fast speed and HSD on.

Open Prevalve slowly.

Flow for 60 seconds

Close Prevalve slowly.

Close run tank isolation valve.

Cycle Prevalve.

Turn off data recording.

This is the end of Test 1.

Inspect and document V-Cone and P2 Snubbers for wet or dry condition. Swap out V-Cone and P2 Snubbers as noted on Test 2 Configuration. 
Fill RP run tank to 2800 gallons minimum.

Turn on SDAS on slow speed.

Pressurize run tank to 40 PSIA

Switch SDAS to fast speed and start Hi-Speed DAS (HSD).

Open Prevalve slowly.

Flow for 60 seconds

Close Prevalve slowly.

Switch SDAS to slow speed and HSD off.

Pressurize run tank to 55 PSIA.

Switch SDAS to fast speed and HSD on.

Open Prevalve slowly.

Flow for 60 seconds

Close Prevalve slowly.

Switch SDAS to slow speed and HSD off.

Pressurize run tank to 70 PSIA.

Switch SDAS to fast speed and HSD on.

Open Prevalve slowly.

Flow for 60 seconds

Close Prevalve slowly.

Close run tank isolation valve.

Cycle Prevalve.

Tum off data recording.

This is the end of Test 2.

Inspect and document V-Cone and P2 Snubbers for wet or dry condition. Do not alter mechanical or measurement system setup pending data review.

Provide all data to MSFC for review 


\section{HTF RP V-Cone Validation Test 3}

Test 3 configuration changes from Test 2 configuration:

Note: If Proof Pressure test (or any other test that will flow gas or RP-1 through the turbine flowmeter) is required, bleed pressure off very slowly or consult Johnny
Heflin at 2565441187 .

Swap P1 with P2 \& close couple P1 to 1 inch port.

Move DP2 (Rosemount) from filter to V-Cone FM \& use close to same sense line length (volume) for both sides of DP2, mount where convenient.

Move DP1, P3, P4 (Stellar) to Filter \& use close to same sense line length (volume) for both sides of DPI, mount where convenient.

Move DP3 from filter to V-Cone \& keep sense line lengths the same as test 2 configuration. Mount DP3 below V-Cone FM

Configure snubbers as shown on HTF RP V-Cone Validation Test 3 Configuration.

\section{Pretest Instructions:} Perform instrument verification for all added measurements per typical SSC verification
procedures.

Verify Close-coupled PI at V-Cone inlet is on SDAS and hi-speed das.

Provide copies of SSC measurement verification procedures to MSFC.

Provide PID list with measurement locations indicated.

Provide capability to catch and accurately measure RP discharge if available.

Photograph in detail, using digital camera, all RP-1 feedline and sensors to be used in validation test to include the following:

-Filter Delta pressures, static pressures, snubbers, senselines and thermocouple.

-Static pressures upstream of V-Cone, close coupled and snubbed with senselines.

-V-Cone, V-Cone delta pressure (Stellar and Rosemount), snubbers, senselines and bleed valves.

Transmit photographs to MSFC for inspection. 
Prime the turbine flowmeter prior to any pressurizing or flow operations. Ensure liquid at ALL TIMES to prevent damage to the turbine meter.

Prime/Bleed both sides of DP1 and DP3 senselines to ensure pure RP-I and no gas present at the snubber and DP. (i.e. ensure the senselines are full of RP up to the DP sensor)

Use MV-MSK-214-RP on level 8 to control RP-1 flow if at all possible, if not possible use the prevalve.

Test 3 if MV-MSK-214-RP is used to control flow, perform the following:

Fill RP run tank to 2800 gallons minimum.

Prime HTF RP V-Cone Validation Test 3 Configuration with prevalve open.

Turn the SDAS on slow speed.

Close prevalve (we want tank fill/drain closed but tank isolation and vent valves open here)

With RP-1 run tank vent open, prevalve closed and no pressure on tank, record 10 seconds of data.

Close RP-1 run tank vent (keep prevalve closed.)

Pressurize run tank to 20 PSIA, hold for 15 seconds. Pressurize run tank to 30 PSIA, hold for 15 seconds. Pressurize run tank to 40 PSIA, hold for 15 seconds. Pressurize run tank to 50 PSIA, hold for 15 seconds. Pressurize run tank to 60 PSIA, hold for 15 seconds. Pressurize run tank to 70 PSIA, hold for 15 seconds. Pressurize run tank to 80 PSIA, hold for 15 seconds. Pressurize run tank to 90 PSIA, hold for 15 seconds. Pressurize run tank to 100 PSIA, hold for 15 seconds. With prevalve closed, vent run tank to Atmospheric pressure. Open prevalve and re prime turbine flowmeter.

Verify minimum of 2800 gallons of RP in Tank Close Facility valve, MV-MSK-2I4-RP (We want prevalve open from here on) and pressurize run tank to 40 PSIA. 
Switch SDAS to fast speed and start Hi-Speed DAS (HSD).

Open MV-MSK-214-RP slowly.

Flow for 60 seconds

Close MV-MSK-214-RP slowly.

Switch SDAS to slow speed and HSD off.

Pressurize run tank to 55 PSIA.

Switch SDAS to fast speed and HSD on.

Open MV-MSK-214-RP slowly.

Flow for 60 seconds

Close MV-MSK-214-RP slowly.

Switch to SDAS to slow speed and HSD off.

Pressurize run tank to 70 PSIA

Switch SDAS to fast speed and HSD on.

Open MV-MSK-214-RP slowly.

Flow for 60 seconds

Close MV-MSK-214-RP slowly.

Close run tank isolation valve and open tank vents.

Open MV-MSK-214-RP and vent line pressure.

Close Prevalue

Close MV-MSK-214-RP

Turn off data recording.

This is the end of Test 3.

Inspect and document DP1, DP3 and P2 Snubbers for wet or dry condition. Do not alter mechanical or measurement system setup pending data review.

Provide all data to MSFC. 
Test 3 if prevalve is used to control flow, perform the following:

Fill RP run tank to 2800 gallons minimum.

Prime HTF RP V-Cone Validation Test 3 Configuration with prevalve open.

Turn the SDAS on slow speed.

Close prevalve See above \& supporting vent/drain valves upstream of the prevalve.

With RP-I run tank vent open See above record 10 seconds of data.

Close RP-I run tank vent. See above

Pressurize run tank to 20 PSIA, hold for 15 seconds.

Pressurize run tank to 30 PSIA, hold for 15 seconds.

Pressurize run tank to 40 PSIA, hold for 15 seconds.

Pressurize run tank to 50 PSIA, hold for 15 seconds.

Pressurize run tank to 60 PSIA, hold for 15 seconds.

Pressurize run tank to 70 PSIA, hold for 15 seconds.

Pressurize run tank to 80 PSIA, hold for 15 seconds.

Pressurize run tank to 90 PSIA, hold for 15 seconds.

Pressurize run tank to 100 PSIA, hold for 15 seconds.

Vent run tank to Atmospheric pressure with prevalve closed.

Open prevalve and re prime turbine flowmeter.

Verify minimum of 2800 gallons of RP in Tank

Close prevalve and pressurize run tank to 40 PSIA.

Switch SDAS to fast speed and start Hi-Speed DAS (HSD).

Open Prevalve slowly.

Flow for 60 seconds

Close Prevalve slowly.

Switch SDAS to slow speed and HSD off.

Pressurize run tank to 55 PSIA.

Switch SDAS to fast speed and HSD on.

Open Prevalve slowly.

Flow for 60 seconds

Close Prevalve slowly.

Switch to SDAS to slow speed and HSD off.

Pressurize run tank to 70 PSIA

Switch SDAS to fast speed and HSD on.

Open Prevalve slowly.

Flow for 60 seconds

Close Prevalve slowly.

Close run tank isolation valve and open tank vents.

Open Prevalve and vent line pressure.

Close prevalve.

Turn off data recording.

This is the end of Test 3.

Inspect and document DP1, DP3 and P2 Snubbers for wet or dry condition. Do not alter mechanical or measurement system setup pending data review.

Provide all data to MSFC. 
HTF RP V-Cone Validation Test 4 Procedure

Test 4 configuration changes from Test 4 configuration:

Note: If Proof Pressure test (or any other test that will flow gas or RP-1 through the turbine flow meter) is required, bleed pressure off very slowly or consult Johnny Heflin at $2565+41187$.

Move DP2 (Rosemount) from above the V-Cone FM to below the V-Cone FM, use close to same sense line length (volume) for both sides of DP2, and mount where convenient with minimum sense line length.

Prime DP2 along with DP3.

Configure snubbers as shown on HTF RP V-Cone Validation Test 4 Configuration.

Pretest Instructions:

Perform instrument verification for all added measurements per typical SSC verification procedures.

Verify Close-coupled P1 at V-Cone inlet is on SDAS and hi-speed das.

Provide copies of SSC measurement verification procedures to MSFC.

Provide PID list with measurement locations indicated.

Photograph in detail, using digital camera, RP feedline and sensors to be used in validation test to include the following:

-V-Cone, V-Cone delta pressure (Stellar and Rosemount), snubbers, senselines and bleed valves/bleed " $B$ " nuts.

Any other sensors that were removed/replaced.

Transmit photographs to MSFC for inspection.

Prime the turbine flowmeter prior to any pressurizing or flow operations. Ensure liquid at ALL TIMES to prevent damage to the turbine meter.

Prime/Bleed both sides of DP1, DP2 and DP3 senselines to ensure pure RP- 1 and no gas present at the snubber and DP. (i.e. ensure the senselines are full of RP up to the DP sensor) 
Test 4

Pretest Instructions: (continued)

Use MV-MSK-214-RP on level 8 to control RP-1 flow if at all possible, if not possible use the prevalve.

Test 4 if MV-MSK-214-RP is used to control flow, perform the following:

Fill RP run tank to 2800 gallons minimum.

Prime HTF RP V-Cone Validation Test 4 Configuration with prevalve open.

Tum the SDAS on slow speed.

Close prevalve (we want tank filldrain closed but tank isolation and vent valves open here)

With RP-1 run tank vent open, prevalve closed and no pressure on tank, record 10 . seconds of data.

Close RP-1 run tank vent (keep prevalve closed.)

Pressurize run tank to 20 PSIA, hold for 15 seconds.

Pressurize run tank to 30 PSIA, hold for 15 seconds.

Pressurize run tank to 40 PSIA, hold for 15 seconds.

Pressurize run tank to 50 PSIA, hold for 15 seconds.

Pressurize run tank to 60 PSIA, hold for 15 seconds.

Pressurize run tank to 70 PSIA, hold for 15 seconds.

Pressurize run tank to 80 PSIA, hold for 15 seconds.

Pressurize run tank to 90 PSIA, hold for 15 seconds.

Pressurize run tank to 100 PSIA, hold for 15 seconds.

With prevalve closed, vent run tank to Atmospheric pressure.

Open prevalve and re prime turbine flowmeter.

Verify minimum of 2800 gallons of RP in Tank

Close Facility valve, MV-MSK-214-RP (We want prevalve open from here on) and pressurize run tank to 40 PSIA. 
Test 4 (continued)

Switch SDAS to fast speed and start Hi-Speed DAS (HSD).

Open MV-MSK-214-RP slowly.

Flow for 60 seconds

Close MV-MSK-214-RP slowly.

Switch SDAS to slow speed and HSD off.

Pressurize run tank to 55 PSIA.

Switch SDAS to fast speed and HSD on.

Open MV-MSK-214-RP slowly.

Flow for 60 seconds

Close MV-MSK-214-RP slowly.

Switch to SDAS to slow speed and HSD off.

Pressurize run tank to 70 PSIA

Switch SDAS to fast speed and HSD on.

Open MV-MSK-214-RP slowly.

Flow for 60 seconds

Close MV-MSK-214-RP slowly.

Close run tank isolation valve and open tank vents.

Open MV-MSK-2।4-RP and vent line pressure.

Close Prevalve

Close MV-MSK-214-RP

Turn off data recording.

This is the end of Test 4.

Inspect and document DP1, DP3 and P2 Snubbers for wet or dry condition. Do not alter mechanical or measurement system setup pending data review.

Provide all data to MSFC. 
Test 4 if prevalve is used to control flow, perform the following:

Fill RP run tank to 2800 gallons minimum.

Prime HTF RP V-Cone Validation Test 4 Configuration with prevalve open.

Turn the SDAS on slow speed.

Close prevalve See above \& supporting vent/drain valves upstream of the prevalve.

With RP-1 run tank vent open See above record 10 seconds of data.

Close RP-I run tank vent. See above

Pressurize run tank to 20 PSIA, hold for 15 seconds.

Pressurize run tank to 30 PSIA, hold for 15 seconds.

Pressurize run tank to 40 PSIA, hold for 15 seconds.

Pressurize run tank to 50 PSIA, hold for 15 seconds.

Pressurize run tank to 60 PSIA, hold for 15 seconds.

Pressurize run tank to 70 PSIA, hold for 15 seconds.

Pressurize run tank to 80 PSIA, hold for 15 seconds.

Pressurize run tank to 90 PSIA, hold for 15 seconds.

Pressurize run tank to 100 PSIA, hold for 15 seconds.

Vent run tank to Atmospheric pressure with prevalve closed.

Open prevalve and re prime turbine flowmeter.

Verify minimum of 2800 gallons of RP in Tank

Close prevalve and pressurize run tank to 40 PSIA.

Switch SDAS to fast speed and start Hi-Speed DAS (HSD).

Open Prevalve slowly.

Flow for 60 seconds

Close Prevalve slowly.

Switch SDAS to slow speed and HSD off.

Pressurize run tank to 55 PSIA.

Switch SDAS to fast speed and HSD on.

Open Prevalve slowly.

Flow for 60 seconds

Close Prevalve slowly.

Switch to SDAS to slow speed and HSD off.

Pressurize run tank to 70 PSIA

Switch SDAS to fast speed and HSD on.

Open Prevalve slowly.

Flow for 60 seconds

Close Prevalve slowly.

Close run tank isolation valve and open tank vents.

Open Prevalve and vent line pressure.

Close prevalve.

Turn off data recording.

This is the end of Test 4.

Inspect and document DP1, DP3 and P2 Snubbers for wet or dry condition. Do not alter mechanical or measurement system setup pending data review.

Provide all data to MSFC. 


\section{APPENDIX B}

\section{HTF RP-1 V-CONE VALIDATION TEST CONFIGURATION}




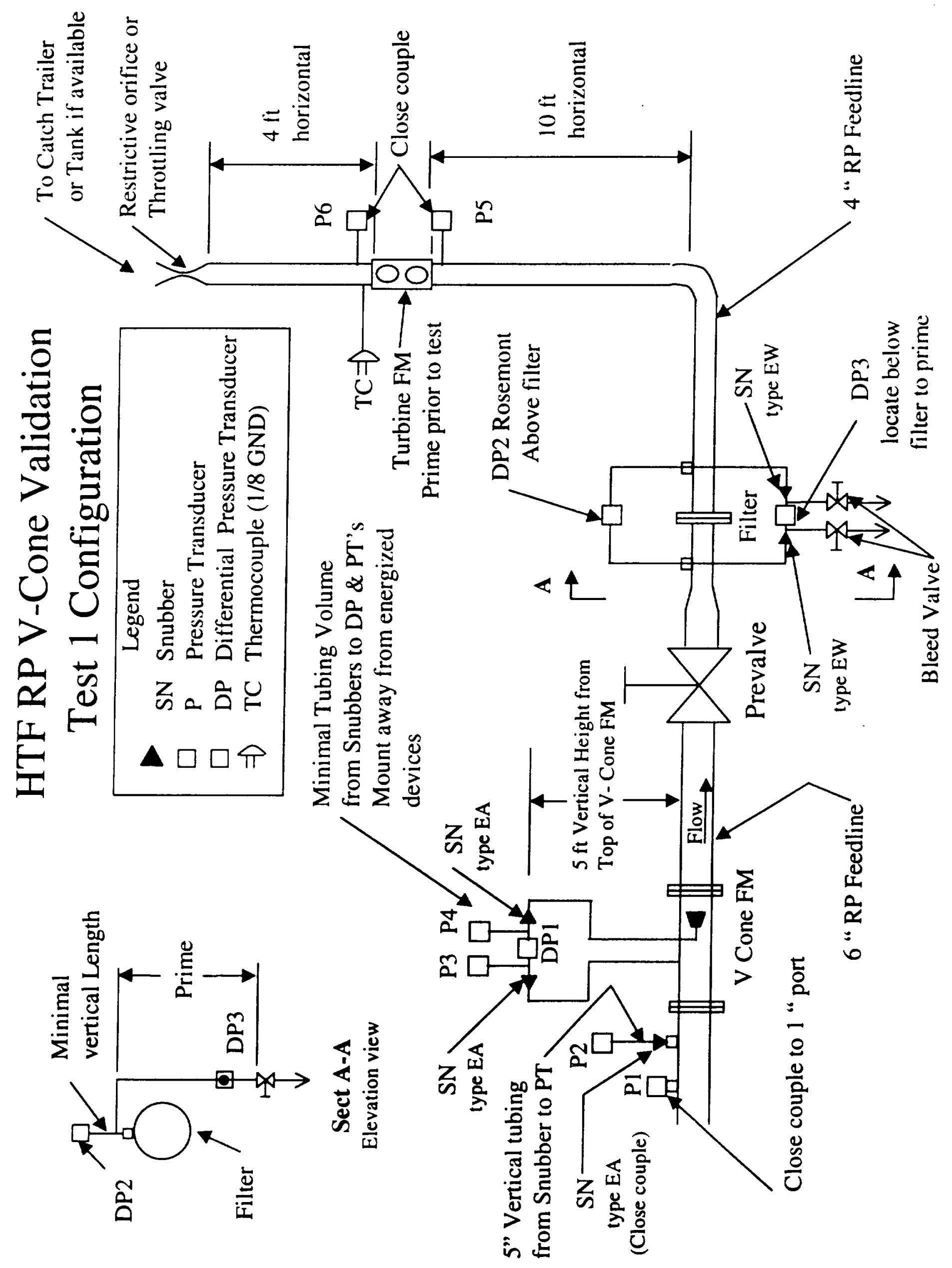




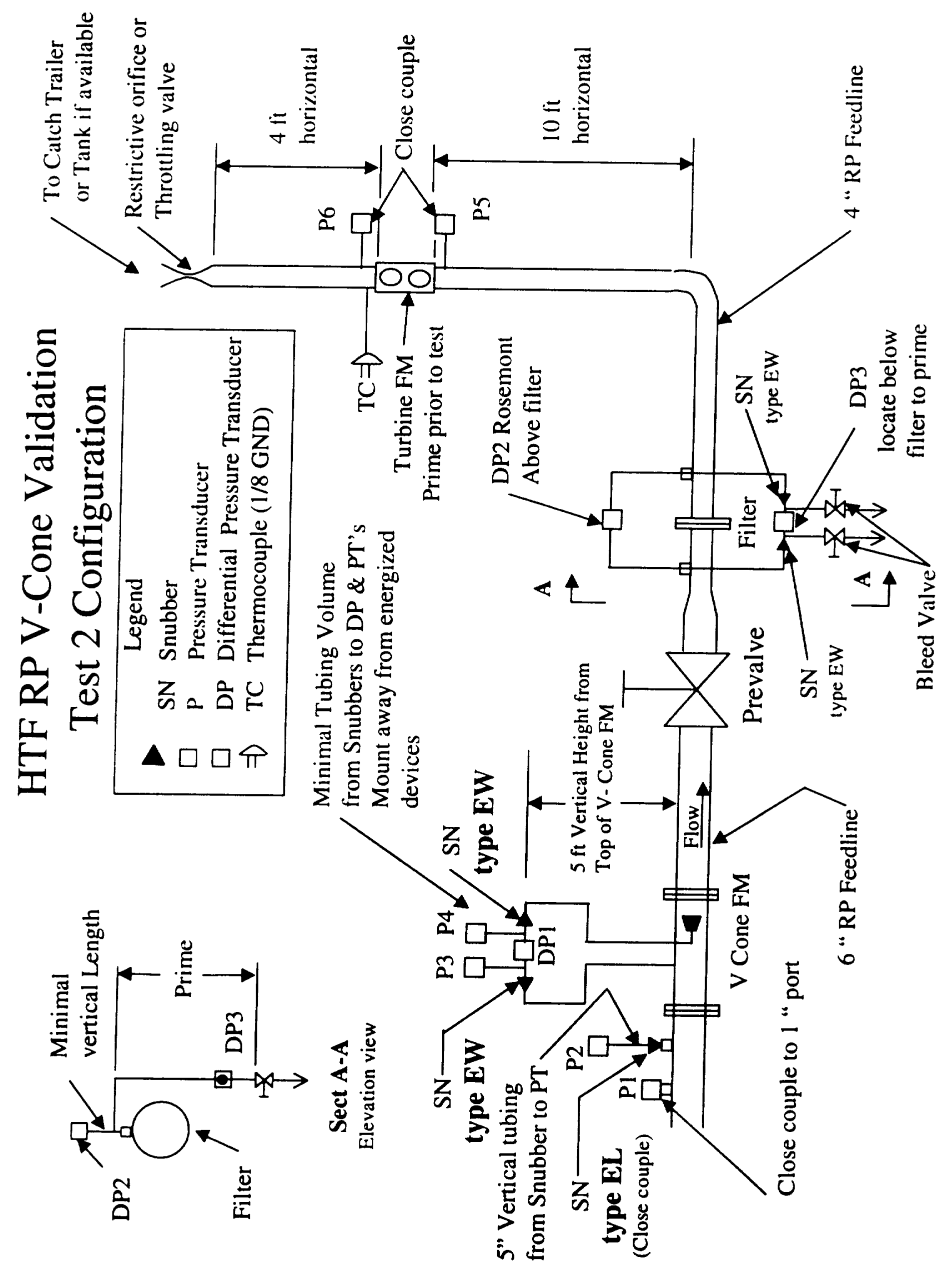




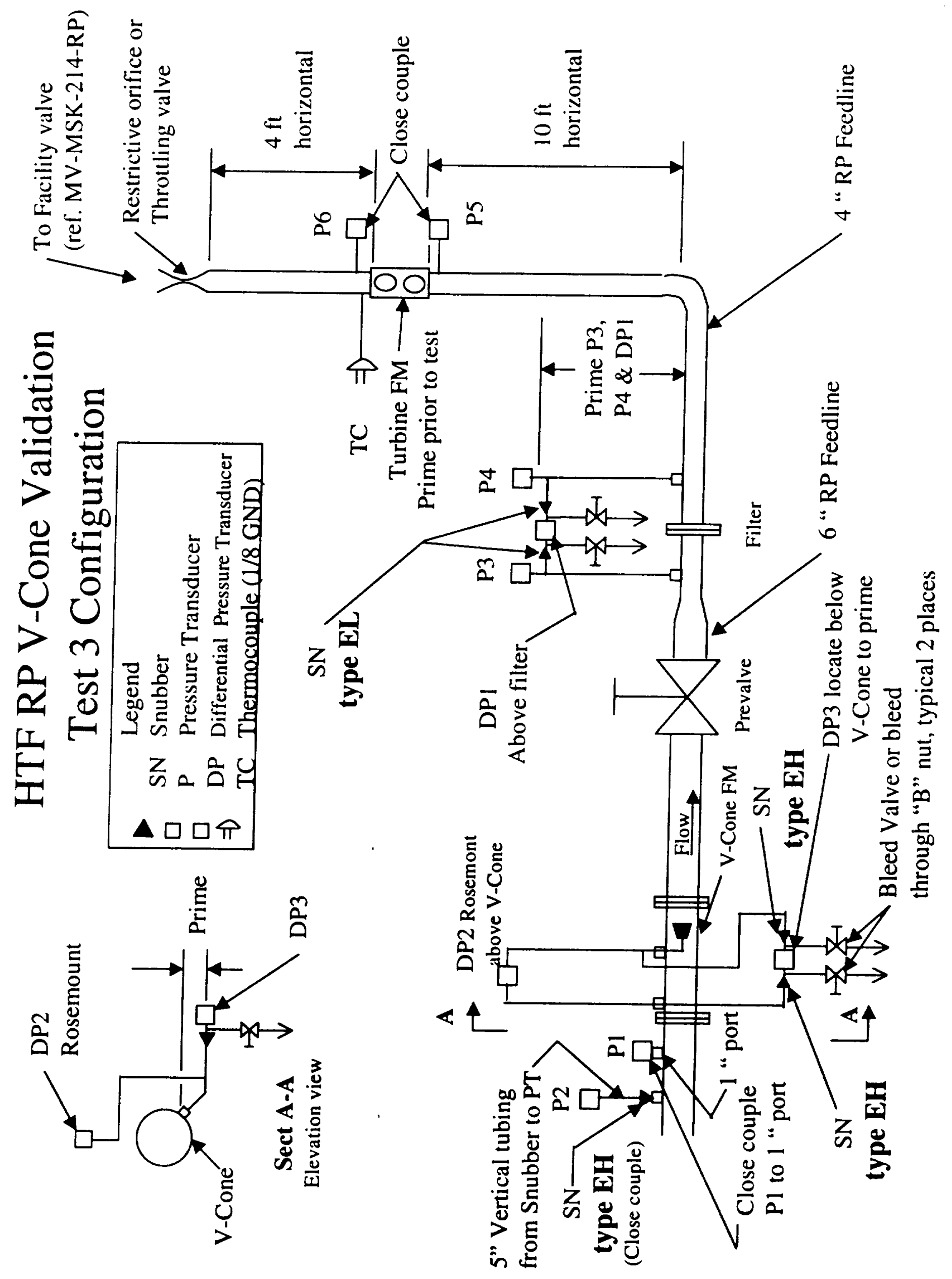




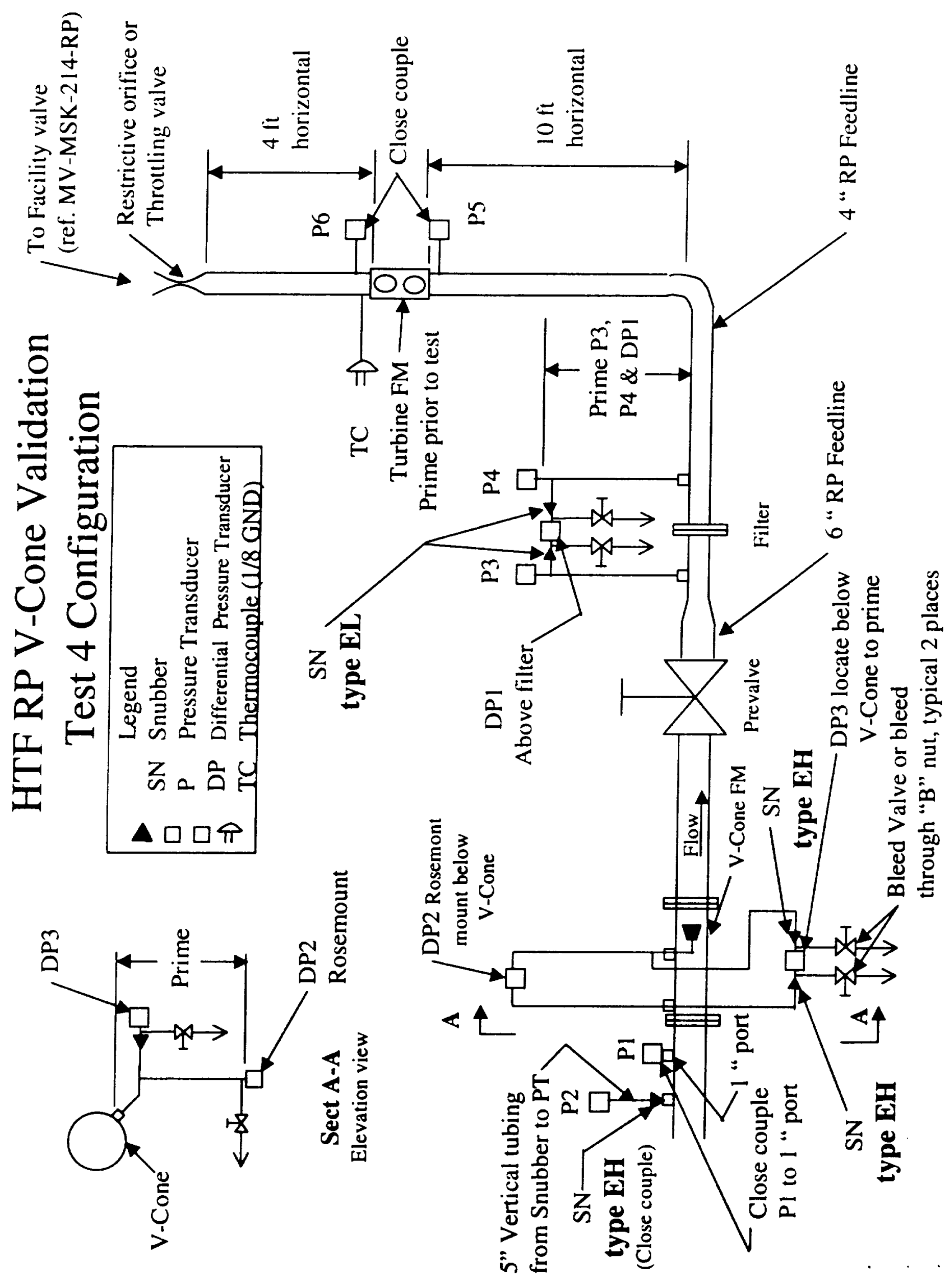

